\title{
Perfil dos usuários da Biblioteca em 2012: necessidade de mediação?
}

Dissertação apresentada à Faculdade de Medicina da Universidade de São Paulo para obtenção do título de Mestre em Ciências

Programa de Fisiopatologia Experimental Orientadora: Profa. Dra. Elnara Márcia Negri

(Versão corrigida. Resolução CoPGr 6018/11, de 01 de novembro de 2011. A versão original está disponível na Biblioteca da FMUSP)

São Paulo

2015 
Dados Internacionais de Catalogação na Publicação (CIP)

Preparada pela Biblioteca da

Faculdade de Medicina da Universidade de São Paulo

Creprodução autorizada pelo autor

\section{Aragão, Marinalva de Souza}

Perfil dos usuários da Biblioteca em 2012: necessidade de mediação? / Marinalva de Souza Aragão. -- São Paulo, 2015.

Dissertação(mestrado)--Faculdade de Medicina da Universidade de São Paulo. Programa de Fisiopatologia Experimental.

Orientadora: Elnara Márcia Negri.

Descritores: 1.Informação 2.Informação em Saúde 3.Mediação da Informação 4.Bibliotecários 5.Competência clínica 6.Competência em informação

7.Sociedade da Informação 8.Conhecimentos, atitudes e prática 9.Descritores

USP/FM/DBD-369/15 


\section{DEDICATÓRIA}


Aos pacientes dos profissionais da saúde do Hospital das Clínicas.

Aos meus sobrinhos que são meus encantos: alegres e otimistas:

Kelly Galeote de Souza, Cleyton de Souza Aragão, Flávia Lopes Aragão, Talita Pignato Aragão, Alessandro Galeote de Souza, Greicy Kelly Santiago e Willy Galeote de Souza (in memorian).

Ao meu pai, Edmundo Moreira Aragão e à minha mãe, Anália de Souza Aragão, à minha irmã Maria de Souza Galeote, que mesmo sem saber da dimensão desse trabalho me entusiasmaram e pelos quais eu sinto imenso amor, orgulho e carinho. 
AGRADECIMENTOS 
A Deus fonte infinita de bondade e sabedoria e por ter-me guiado neste momento tão importante da minha vida. E à Sua Mãe Santa Maria.

À Anneliese Carneiro da Cunha que me recebeu na Faculdade de Medicina e me ensinou a tratar os pesquisadores profissionalmente e a rir das situações mais complicadas.

À Chefe Técnica do Sistema Integrado de Bibliotecas (SIBi) - Profa. Dra Maria Fazanelli Crestana que incentivou começar este projeto.

À minha orientadora Profa. Dra. Elnara Márcia Negri que me incentivou, tratou-me com carinho, respeito e compreensão e acreditou no meu potencial. Me deu a mão e não me deixou desistir.

À Suely de Campos Cardoso, mais que coorientadora, minha madrinha, ajudou-me material e moralmente, gastou horas comigo inclusive aos domingos.

À Profa. Dra. e colega Cibele Marques dos Santos que de uma só vez delineou este Projeto, obrigada pelo profissionalismo, respeito e carinho.

À Fabíola Rizzo Sanchez que com imensa paciência ensinou-me a usar as ferramentas mais complexas.

À Talita Carvalho da Mota e Silva e ao Marcelo pelos gráficos e tabelas. 
À Tania Regina de Souza, Igor Tolgyesi e Vanda Mariscal secretários do Programa Fisiopatologia Experimental, por todo apoio, amizade, competência e boa vontade, fundamentais para a conclusão deste trabalho.

Às colegas Valéria de Vilhena, Márcia Maria de Arruda, Rogéria Cristina Dias, Aparecida Elizete de Assis Araújo Santos, que me incentivaram e me substituíram no trabalho quando eu tive de ausentar-me.

Aos que literalmente me empurraram e ao mesmo tempo me ampararam quando pensei que não concluiria: Elza Katayama, Heloísa Vianna, Helena Kawamura, Miriam Mirna, Maria Cecília Coutinho Arruda, Maria Ascenção Apolônio, Paula Lencastre e Nilza Lucinda de Ramos Filha.

A Regina Lopes Teixeira e a Dona Lalinha (in memorian) que torceram por mim e queriam ver este trabalho realizado.

Ao Dr. Nilo Bozzini que com palavras de afeto outras nem tanto, insistiu para que eu trilhasse esse caminho. Agradeço também aos seus "pupilos" que me ajudaram na primeira fase.

Agradecimentos especiais a todos que, de alguma forma, abriram mão de minha presença, no trabalho ou no lazer que passaram pela minha vida e participaram da construção de quem sou hoje.

Obrigada a todos que gastaram tempo lendo e colaborando com este projeto. 
EPÍGRAFE 
Habitua-te a elevar o coração a Deus em ação de graças, muitas vezes ao dia. - Porque te dá isto e aquilo. - Porque te desprezaram. - Porque não tens o que precisas, ou porque o tens. Porque fez tão formosa a sua Mãe, que é também tua Mãe. - Porque criou o Sol e a Lua e este animal e aquela planta. - Porque fez aquele homem eloquente e a ti te fez difícil de palavra...

Dá-Lhe graças por tudo, porque tudo é bom.

São Josemaria Escrivá , Caminho, 268. 
SUMÁRIO 
Listas

Resumo

Summary

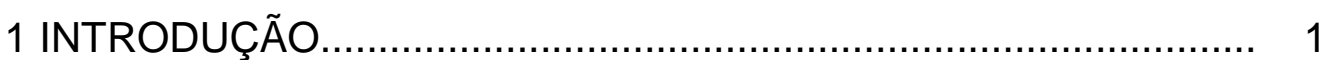

2 REVISÃO DE LITERATURA................................................ 9

2.1 O bibliotecário mediador........................................................ 13

2.2 Sociedade da informação................................................... 15

2.3 Descritores......................................................................... 18

2.4 Information needs.......................................................... 19

2.4.1 Alunos de graduação: medicina e para-médicos..................... 21

2.4.2 Pós-graduandos............................................................. 22

2.5 Informação e conhecimento.................................................. 23

2.6 Competência.................................................................... 26

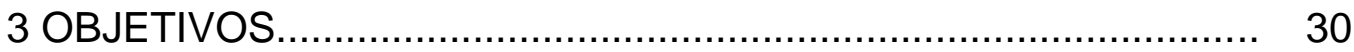

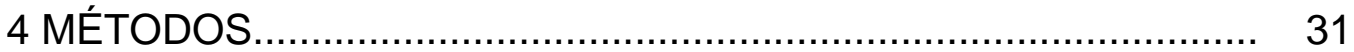

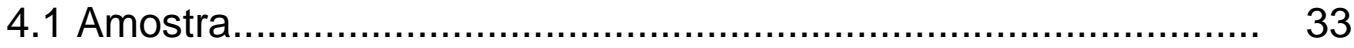

4.2 Questionário................................................................... 33

4.3 Critérios de inclusão............................................................. 34

4.4 Análise dos dados............................................................ 34

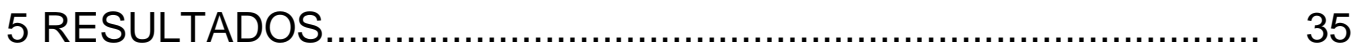

5.1 Caracterização da população............................................. 37

5.2 Influência da mediação no comportamento da população estudada.................................................................. 43

6 DISCUSSÃO ..................................................................... 45

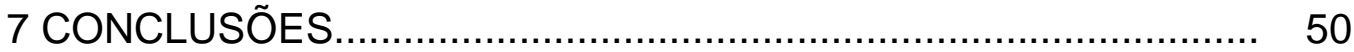

8 CONSIDERAÇÕES FINAIS ........................................... 52

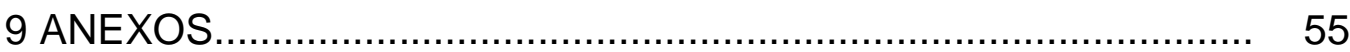

10 REFERÊNCIAS............................................................. 61

BIBLIOGRAFIA CONSULTADA .............................................. 69 


\section{Listas}




\section{LISTA DE ABREVIATURAS E SIGLAS}

$\begin{array}{ll}\text { ALA } & \text { American Library Association } \\ \text { BDTD } & \text { Biblioteca Digital de Teses e Dissertações } \\ \text { BIREME } & \text { Biblioteca Regional de Medicina } \\ \text { CPG/FMUSP } & \text { Central de Pós-Graduação da Faculdade de Medicina da } \\ & \text { Universidade de São Paulo } \\ \text { CAPPesq } & \text { Comitê de Ética para Análise de Projetos e Pesquisa } \\ \text { DBD/FMUSP } & \begin{array}{l}\text { Divisão de Biblioteca e Documentação da Faculdade de } \\ \text { Medicina da Universidade de São Paulo }\end{array} \\ \text { DeCS } & \text { Descritores em Ciências da Saúde } \\ \text { FM/USP } & \text { Faculdade de Medicina da Universidade de São Paulo } \\ \text { LIMs } & \text { Laboratórios de Investigação Médica } \\ \text { SAI/FMUSP } & \text { Serviço de Atendimento e Informação } \\ \text { VPN } & \text { Virtual Private Network }\end{array}$




\section{LISTA DE GRÁFICOS}

Gráfico 1. Sexo dos respondentes................................................ 37

Gráfico 2. Idades dos respondentes................................................ 38

Gráfico 2.1. Idade dos respondentes separada por sexo....................... 38

Gráfico 3. Distribuição da população deste estudo de acordo com a profissão........................................................................ 39

Gráfico 4. Atuação dos respondentes de acordo com o sexo................... 39

Gráfico 5. Frequência de utilização das bases de dados......................... 40

Gráfico 6. Fontes de pesquisa utilizadas........................................... 40

Gráfico 7. Bases de dados utilizadas.................................................. 41

Gráfico 8. Utilização de resumos...................................................... 41

Gráfico 9. Meios para busca do artigo completo................................... 42

Gráfico 10. Uso de descritores........................................................ 42

Gráfico 11. Treinamento na Biblioteca........................................ 43 


\section{LISTA DE TABELAS}

Tabela 1 - Distribuição de sexo e profissão da população estudada.................. 38

Tabela 2 - Uso de descritores e treinamento crosstabulation.......................... 43

Tabela 3 - Distribuição do sexo dos participantes em relação à mediação........ 44

Tabela 4 - Profissão e mediação............................................................. 44

Tabela 5 - Frequência de visitas à biblioteca em relação à mediação............... 44

\section{LISTA DE FIGURAS}

Figura 1. Bibliotecários e tecnologia............................ 12

Figura 2. Informação vs conhecimento..................................... 25 
RESUMO 
Aragão MS. Perfil dos usuários da Biblioteca em 2012: necessidade de mediação? [Mestrado]. São Paulo, 2015. Programa de Fisiopatologia Experimental da Faculdade de Medicina da Universidade de São Paulo.

Introdução: O ser humano na sua condição social, precisa necessariamente da intervenção de outro ser nas suas funções. Na área da saúde, o profissional, vivencia situações e diante do acúmulo de informações recuperadas na Internet, necessita de um mediador que torne possível transformar essa informação em conhecimento. Nos últimos 20 anos, temos verificado um aumento gradativo e descontrolado na quantidade de documentos bibliográficos em todas as áreas do conhecimento, mas especialmente na biomédica. Objetivo: Considerando que a internet e a tecnologia da informação são amplamente disponíveis atualmente, alguns estudos sugerem que as bibliotecas e os bibliotecários podem vir a se tornar instituições obsoletas no cenário acadêmico. $\mathrm{O}$ objetivo do presente estudo foi analisar o perfil de usuários da biblioteca em nossa instituição, além de tentar verificar o papel da mediação informal desempenhada pelos bibliotecários neste contexto. Métodos: 570 usuários da Biblioteca da FMUSP, que visitaram nossa biblioteca no período de dezembro de 2012 a Abril de 2013, foram convidados a responder um breve questionário, sobre seus hábitos de busca de conhecimentos na literatura. O questionário foi mandado e respondido por e-mail. O perfil destes usuários foi analisado e a seguir, os participantes foram divididos em 2 grupos. Grupo $1 \quad(n=190)$ : receberam qualquer auxilio do bibliotecário durante suas buscas, grupo 2 ( $\mathrm{n}=$ 52): acessaram a informação de maneira independente, sem a mediação do bibliotecário. Analisamos algumas características destes dois grupos. Resultados e conclusões: O presente estudo permitiu caracterizar que a maioria dos usuários que compareceu à biblioteca era do sexo feminino e que estão na faixa etária entre trinta e quarenta anos, sendo na maioria médicos jovens e estudantes de medicina, habituados a usar as bases de dados. A maioria recebeu algum tipo de mediação formal ou informal dos bibliotecários no acesso à informação. Sendo que este auxílio pode ter influenciado no uso de descritores em suas buscas. Com esta pesquisa, foi possível avaliar algumas das necessidades informacionais dos respondentes. Tais informações aliadas à extensa revisão da literatura podem ser úteis para balizar futuras intervenções dos profissionais da biblioteca para otimizar seu papel na mediação. Não foram observadas diferenças entre os grupos.

Descritores: Mediação, Informação, Competência clínica, Questionários. 
SUMMARY 
Aragão MS. Profile of users of the Library in 2012: is necessary mediation? [Master]. São Paulo, 2015. Programa de Fisiopatologia Experimental da Faculdade de Medicina da Universidade de Sao Paulo.

Introduction: Human beings in their social condition necessarily need the intervention of another being in his duties. In healthcare, professional, experiences and situations before the accumulation of information retrieved on the Internet, you need a broker that makes it possible to transform this information into knowledge. Over the past 20 years, we have seen a gradual and uncontrolled increase in the amount of bibliographic documents in all areas of knowledge, but especially in biomedical. AIMS: Considering that the internet and the information technology are widely available nowadays, some studies suggest that libraries and librarians may become obsolete in the academic scenery. The purpose of the present study was to access the profile of library users in our institution, as well as to evaluate the need for mediation by the librarians in a Medical School. METHODS: 570 individuals that visited our library from December 2012 to April 2013 were invited to respond to a brief questionnaire addressing their habits when pursuing scientific information. The questionnaire was sent and responded by email. 419 participants were post graduate students and the others were physicians from our institution. The population was divided in two groups. Group $1(n=190)$ : submitted to library training in searching information, group $2(n=52)$ : accessed information by themselves without mediation. We analyzed the differences in behavior between those two groups. RESULTS AND CONCLUSIONS: The majority of individuals that used our library were, females, with a mean age of 39 years and most of them physicians or medical students. The great majority were frequent users and had personal experience in the library before. No differences in behavior were observed between groups in terms of frequency, data base, or use of key words. The present work has inumerous limitations, but may useful inhelping librarians improve their technique facing the new era of information.

Descriptors: Mediation; Information; Information needs; Clinical competence; Questionnaire. 
1 INTRODUÇÃO 
O termo mediação é usado em várias áreas do conhecimento. Para a Filosofia, mediação é o processo criativo, mediante o qual se passa de um termo inicial a um termo final, enquanto, para a Psicologia, mediação é uma sequência de elos intermediários (estímulos e respostas) numa cadeia de ações, entre estímulo inicial e a resposta verbal no final do circuito (Perrotti, 2007). O termo mediação aparece no Direito, na Religião, sempre no sentido de colocar em relação, aproximar, criar pontes entre elementos. Oriundo do latim mediare que significa estar no meio, interpor-se (Moraes, 2012). É a intervenção em uma situação no intuito de reconciliar as partes.

A mediação é parte integrante da condição social do ser humano. A relação do homem com o mundo não é direta, mas essencialmente mediada, necessitando da presença de um elemento mediador, do qual a linguagem é o signo principal (Silva, 2009).

Do ponto de vista da informação, o homem não nasce sabendo ser homem. Ele aprende. E esse aprendizado se dá por meio da apropriação de informações do contexto social (Neves, 2011).

Este fato não é diferente no cenário da busca da informação, em que o avanço tecnológico faz da informação um elemento em mutação a cada instante. Assim, a informação biomédica das fontes de pesquisa atualiza-se continuamente, o que exige que o profissional da informação esteja capacitado, por um lado para entender as necessidades do pesquisador e, por outro, dominar as fontes e ferramentas que compõem esse universo. Dentre as várias acepções do termo mediação, será usada aquela que designa o processo básico de atividade do bibliotecário ao intervir na cadeia informaçãoconhecimento, para confrontar as necessidades informacionais do pesquisador com as diversas ferramentas de que se dispõe (Garcia, 2011).

Há, portanto, várias possibilidades de se abordar a mediação. Neste trabalho decidiu-se descrever como se dá o processo básico da atividade do bibliotecário, ao intervir no processo informação-conhecimento, buscando entender as necessidades informacionais do pesquisador $e$ as diversas ferramentas de que dispõe. 
Nos últimos 20 anos, temos verificado um aumento vertiginoso e descontrolado da quantidade de documentos bibliográficos em todas as áreas do conhecimento, especialmente na área biomédica. Se há um aumento na literatura, não é diferente no que diz respeito aos recursos na tecnologia e nas ferramentas desta busca. Grande quantidade de material versus tecnologia indica que a pesquisa deve contar com instrumentos adequados para que nada se perca, mas também para que o resultado seja relevante. Lauritsen e Moller (2006) afirmam que a estimativa é de que mais de dois milhões de artigos científicos são publicados anualmente nos periódicos biomédicos.

Em 1994, quando ingressei na Biblioteca da Faculdade de Medicina, usávamos os CD-ROM(s). Cada um continha resumos publicados em um período de cinco anos. A cada um desses períodos conforme requeria a pesquisa, trocávamos o CD-ROM. Quando sofriam algum dano, eram centenas de informações que se perdiam. Ainda há os que contam que tiravam cópias e mais cópias das fontes de informação impressas e corriam atrás do artigo completo. Quando não se dispunha do artigo no acervo da Biblioteca ou de outras bibliotecas do sistema, era necessário solicitar no exterior, o que impunha um ônus financeiro bastante considerável. Em algumas situações ainda há necessidade de solicitar artigos no exterior, mas é bem pequena a demanda.

Passamos também, pela fase em que criávamos o perfil do pesquisador, tirávamos cópias dos sumários das revistas, enviávamos estas cópias pelo correio ou levávamos os disquetes em mãos para outros pesquisadores que participavam do processo. Quando o pesquisador devolvia a cópia com o artigo assinalado, enviávamos o artigo completo pelo correio ou pessoalmente a seus laboratórios ou LIMs (Laboratórios de Investigação Médica).

Os obstáculos que se apresentam no acesso à informação podem ser de ordem física ou virtual. O usuário pode saber o que quer, mas barreiras de tempo e espaço, impedem-no de alcançar o seu objetivo. Há um princípio de descontentamento quando ao final de uma busca chega-se a resumos 
recuperados nas diferentes bases de dados e não se obtém o documento completo. Sem o acesso ao documento integral, torna-se frustrante a busca pela informação necessária, normalmente, para se solucionar um problema com algum paciente ou para alcançar maior atualização na respectiva área de atuação.

Esse acesso físico pode ocorrer a partir do acesso presencial aos recursos informacionais de uma dada instituição ou mediante serviços de intercâmbio e comutação, que permitem aos usuários o manejo do artigo ou capítulo completo de livros.

Para esta dissertação, levou-se em conta o comportamento dos pósgraduandos Strictu senso (mestrado/doutorado) e de outros profissionais da saúde, que diariamente, buscam informação científica na Divisão de Biblioteca e Informação da Faculdade de Medicina da Universidade de São Paulo.

Brettle et al. (2007) destacam que compete ao bibliotecário ocupar-se também de treinar o profissional que busca a informação, e não apenas dar-Ihe o trabalho pronto, uma vez que essa busca de material poderá ocorrer em momentos em que o bibliotecário não esteja disponível. Verifica-se que o público, de modo geral, desconhece esse tipo específico de ajuda, o que explica em parte, a timidez de muitos usuários ao deixarem de solicitar assessoria, aumentando o tempo de pesquisa gasto nos bancos de dados ou no acervo da biblioteca (Dee, 2005; Brettle et al., 2007).

Conclui-se, a partir da observação do dia-a-dia de uma biblioteca, que somente uma pequena porcentagem de usuários não necessita dessa ajuda. São os pesquisadores ou usuários já treinados, ou com o hábito de frequentar a biblioteca e tendo o respectivo domínio dos recursos eletrônicos (Brettle et al., 2007; Sousa, 2009).

Diariamente, verifica-se a necessidade de um profissional para assessorar o usuário, seja na tomada de decisão sobre qual base de dados consultar, seja na escolha e determinação dos descritores. Contudo, ainda é comum ouvir esta frase: "é a primeira vez que venho à biblioteca, você pode me ajudar?". 
Não basta o acesso ilimitado à informação, concedida atualmente pela Internet, é preciso, discernir e tirar o máximo proveito dessas informações e transformá-las em conhecimento, capaz de mudar a realidade e o comportamento de quem busca informação. Presume-se, assim, que o conhecimento pode ser entendido como o principal resultado da mediação da informação (Sherman, 2007; Ferreira; Almeida Júnior, 2013).

Miranda et al. (2010) mencionam que a primeira geração da Web foi projetada exclusivamente para consumo geral, sem preocupação com a exatidão. Já na década de 90 , dá-se um crescimento vertiginoso nos anúncios e vendas de produtos pela Internet. Cresceu a credibilidade nas informações recuperadas, e atualmente os serviços são fornecidos para pesquisadores. A evolução dos recursos, levou os bibliotecários, especialmente nas bibliotecas de ciências da saúde, a se adaptarem ao dinamismo das novas tecnologias e fontes de informação.

De acordo com Miranda et al. (2010), que se baseiam na articulação entre a informação tecnológica e o uso de descritores, retirados de thesaurus, os bibliotecários estão perfeitamente capacitados para gerenciar as ferramentas da Web 2.0. Segundo os autores o profissional da informação, isto é, o bibliotecário, pode e deve seguir a progressão contínua das gerações da Web. Importa que o profissional enfrente o desafio de seguir as tendências, as mudanças das tecnologias e dos usuários, adiantando-se para poder atender a suas expectativas. Devem trabalhar, o bibliotecário e o pesquisador, para compartilhar ideias e experiências no desenvolvimento das ferramentas da Web.

Assim como a Web, as ferramentas e as necessidades informacionais são dinâmicas. O bibliotecário deve estar disposto a acompanhar as mudanças participando ativamente do processo de mediação. Para Miranda et al. (2010), é tão imprescindível essa transformação que ela recebe a denominação de information service professional, para designar o novo papel do bibliotecário, inserido na sociedade da informação; ela prepara-o igualmente para atender ao novo tipo de usuário que, agora, busca a informação antes mesmo que seja 
publicada. Verifica-se, diariamente, a demanda de profissionais da saúde que, na saída de uma reunião com seus pares, dirigem-se à biblioteca, procurando um artigo comentado e que ainda não foi publicado nas revistas científicas.

A competência do profissional da informação cresce em função do domínio de duas vertentes: conhecimento do perfil do usuário, isto é, de suas necessidades informacionais e do acervo impresso ou virtual de que dispõe, bem como das ferramentas adequadas para o acesso rápido à informação em benefício do trabalho científico (Brettle et al., 2007).

Para Arellano (2001), o profissional da informação precisa trabalhar junto aos sistemas online atingindo a meta comumente conhecida de auxiliar o usuário a ter acesso ao conhecimento produzido na área de seu interesse. A tendência, nos últimos anos, foi de crescimento tanto de softwares quanto do público com necessidades informacionais específicas.

Assim, entende-se a mediação como a "intervenção humana para assistir a busca de informação e aprendizagem a partir do acesso à informação e uso", de modo que o mediador é "uma pessoa que ajuda, guia, orienta e intervém no processo de busca da informação de outra pessoa ou instituição" (Kuthlthau, 1999).

A biblioteca é considerada ainda um local importante para a contribuição ao acesso à informação. Procurar demonstrar o valor dos acervos das bibliotecas universitárias não é um retrocesso e sim uma contribuição para a qualidade do ensino superior que continua a ser um foco de debate nacional. Além das bibliotecas acadêmicas, ou de pesquisa é grande a contribuição delas as para cumprir a missão e os objetivos institucionais.

No Brasil, há décadas vimos lutando para que se construam bibliotecas escolares e tenham bibliotecários, somando-nos assim aos esforços de criar e desenvolver o hábito de leitura acostumando o usuário a continuar frequentando as bibliotecas acadêmicas.

Apresentamos alguns argumentos que provam que a biblioteca não é um termo obsoleto em comparação com a Web (Sherman, 2007): 
- Nem tudo é armazenável na Web, é ilusão pensar que um dia todos os documentos nos mais variados suportes estarão disponíveis online. Google books reconhece isso: há muito conhecimento impresso nos acervos das bibliotecas e alguns não estão em condições de serem digitalizados;

- O cidadão participa da democratização do conhecimento quando comparece a uma biblioteca pública e nem todos têm acesso a Internet gratuitamente;

- A Web supõe o acervo das bibliotecas, mas não os substitui. É sem dúvida um grande recurso para obter informação, mas na Web ela está espalhada ao passo que na biblioteca está organizada, classificada;

- As bibliotecas não estão constituídas apenas de livros: a tecnologia está sendo integrada nos sistemas de bibliotecas, por exemplo a aquisição de e-books e a Biblioteca interativa da DBD/FMUSP. Poderíamos eventualmente ver pilhas inteiras dos acervos das bibliotecas sendo relegado para bancos de dados; ou seja documentos acessados apenas digitalmente. Então, onde é que isso deixa de comprometer os bibliotecários? Estão sendo ultrapassados pela tecnologia?;

- Dispositivos móveis não marcam o fim dos livros impressos ou dos acervos das bibliotecas, como querem mostrar algumas previsões do "fim do livro", a digitalização e outras tecnologias. Os e-books para download nos dispositivos móveis facilitam a pesquisa em qualquer lugar e acompanham a geração atual (y ou z), mas e-books não são uma transição que tudo permite aos leitores. $O$ rádio vive apesar da TV, os filmes ainda estão em alta demanda, apesar do vídeo, as pessoas ainda falam ao telefone, apesar do e-mail. Pessoas que gostam de livros em suporte papel vão continuar a ler livros impressos, mesmo fazendo downloads e usando dispositivos móveis. Haverá cada vez mais solicitações às editoras para que 
publiquem e-books em vez de papel. Afinal de contas, uma imensa acumulação de livros impressos ainda estará acessível aos leitores;

- As bibliotecas, em seus setores de aquisição, para atender satisfatoriamente seus leitores, continuam a assinar e manter uma vasta lista de periódicos e jornais acadêmicos importando publicações e arquivando os fascículos anteriores. Esse esforço permite que o acervo se mantenha completo. Por outro lado, manter assinaturas de periódicos supõe a compra da coleção completa e ao renovar a assinatura, é necessário comprar todos os números anteriores;

- Além do acervo próprio, a Biblioteca pode conseguir publicações por meio de empréstimo-entre-bibliotecas ou pela comutação nacional/internacional e os periódicos por assinatura online, desaparecem, tornam-se offline ou cada vez mais caros impossibilitando a renovação da assinatura.

A sociedade não está preparada para abandonar a biblioteca tradicional ou híbrida e provavelmente nunca estará. Bibliotecas podem adaptar-se às mudanças sociais e tecnológicas, mas não podem ser substituídas. As bibliotecas são diferentes da Web e os bibliotecários estão aptos para auxiliar os estudantes, pesquisadores e os cidadãos em geral para melhor compreensão e o modo de encontrar a informação seja ela impressa ou online. 
2 REVISÃO DE LITERATURA 
Vale a pena citar as Leis de Ranganathan (matemático indiano), embora essas cinco leis da Biblioteconomia tenham sido enunciadas em 1931, vigoram até os dias de hoje.

Essas leis, extraídas do livro: The Five Laws of Library Science (1931), onde se abordam questões da Biblioteconomia moderna - dizem respeito ao uso de livros, de documentos ou de artigos de periódicos. Elas podem ser resumidas da seguinte forma:

1. Os livros existem para ser usados. O livro é um meio que impulsiona o conhecimento. "Quem tem informação, tem poder". O livro deve ser encarado como um meio e não como um fim;

2. Todo livro tem seu leitor. O êxito desse combinado encontro depende da difusão da informação. Deve-se divulgar os livros existentes em cada biblioteca;

3. Todo usuário tem seu livro. O bibliotecário deve conhecer bem seus usuários, observando-os, entrevistando-os para preparar-lhes o acervo adequado. A seleção do material deve estar de acordo com o perfil do leitor;

4. Poupe o tempo do usuário. Uma boa preparação e arrumação dos documentos, diminui o tempo necessário para encontrar a informação desejada;

5. Uma biblioteca é um organismo em crescimento. Compete ao bibliotecário nortear esse crescimento, mediante a verificação do que é mais solicitado. São relevantes as estatísticas de consulta e empréstimo para o dinamismo.

Seja no século passado, seja no atual, nos quais as ferramentas eletrônicas mais se destacam, o bibliotecário continua a ser o mediador que viabilizará o acesso ao documento em tempo hábil.

Há diferentes formas de auxiliar o usuário. Cada um apresenta suas peculiaridades quer no modo de pedir ajuda quer quanto ao nível em que deseja ser assessorado. Mudanças nas práticas da medicina e no 
desenvolvimento tecnológico oferecem aos bibliotecários sempre novas oportunidades de selecionar e organizar os recursos eletrônicos, segundo as necessidades dos pesquisadores. Há grande quantidade de material na Internet, mas sua disposição não segue critérios objetivos. Segundo Blansit e Connor (1999), o domínio das várias estratégias de consulta permite ao bibliotecário estar à altura das necessidades do pesquisador. A atuação do bibliotecário junto aos fornecedores de material eletrônico possibilitará a aquisição mais precisa e rápida do material (Figura 1).

De acordo com Ferreira (2003), os sistemas de gestão de informação têm por finalidade fornecer informações relevantes para os tomadores de decisão, e, por isso a sua principal função é a de coletar, processar e disseminar informação, isto é, filtrar a informação.

Para Almeida Júnior (2008), o termo mediação bastante citado neste trabalho, refere-se aos planos das práticas do fazer profissional, ligado às práticas do atendimento ao usuário da unidade de informação. Considera-se, portanto, a mediação como uma ponte "que permite a relação entre dois pontos que, de alguma forma, estão impedidos de interagir por obstáculos e/ou empecilhos".

Para Rodrigues e Crippa (2011), não há uma única definição e nem uma linha de pensamento que trabalhe as noções de mediação. As mais diversas áreas do conhecimento apropriam-se dela e trabalham parte de seus possíveis sentidos. Para o senso comum, a mediação é vista como a ação de servir de intermediário. Aquilo ou aquele que está no meio, entre dois pontos, interligando-os. Para esses autores, portanto, a mediação, na prática biblioteconômica, refere-se ao papel do bibliotecário especialista em alguma área do conhecimento, que se propõe a auxiliar o profissional da saúde a encontrar a informação no contexto de sua pesquisa em tempo hábil. $A$ mediação é complexa e envolve outras noções: informação, comunicação, tecnologia (dispositivo técnico) etc. A mediação, enquanto transmissão de informação, pode tornar-se bastante subjetiva, pois a definição da informação fica a cargo do profissional que presta este serviço. 


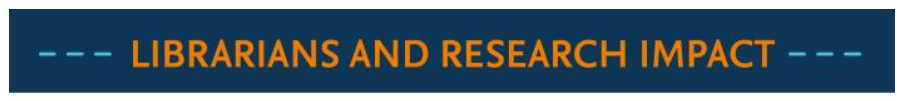

A story of measurement, insights and action

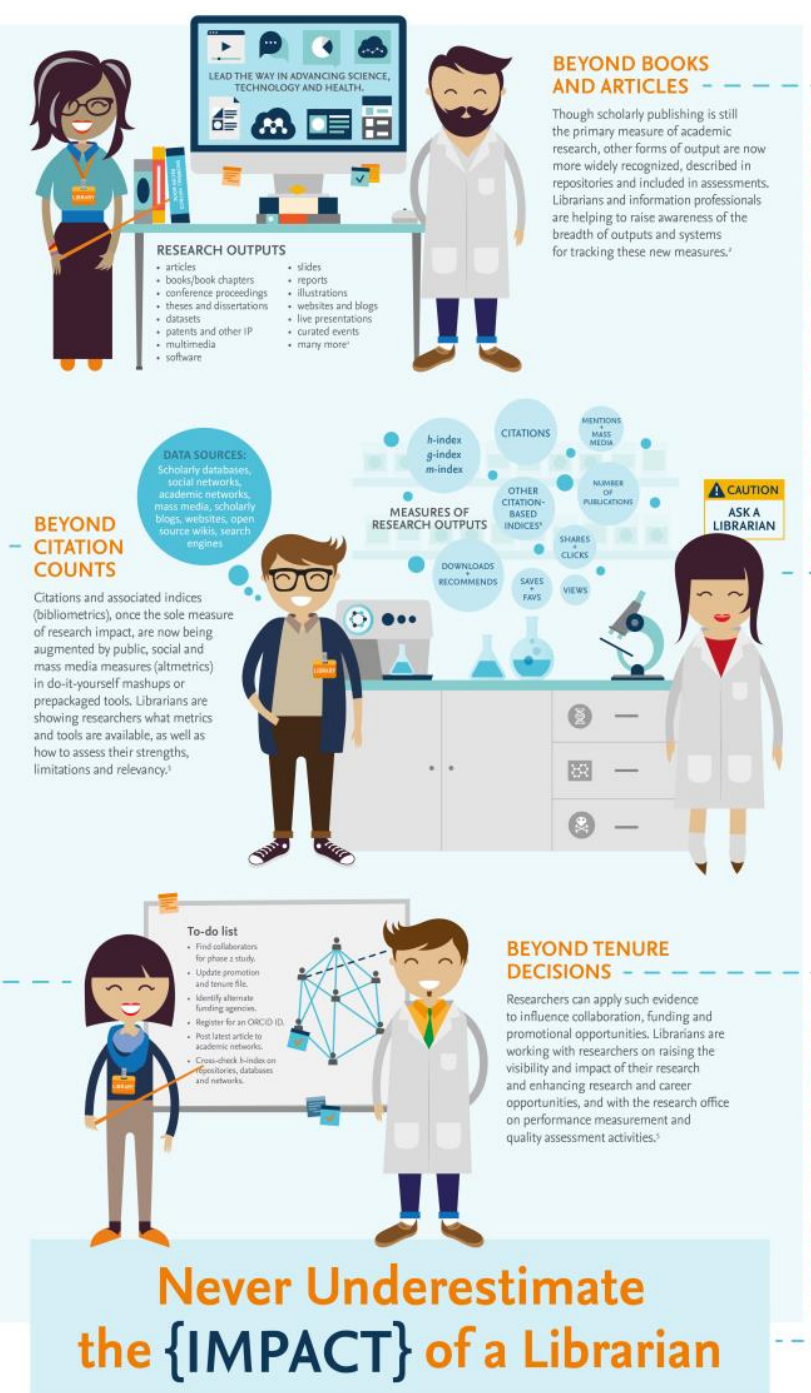

REFERENCES

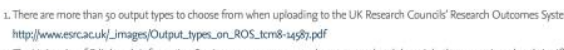

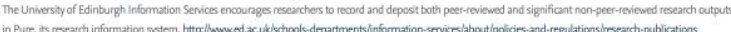

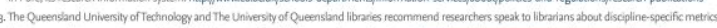

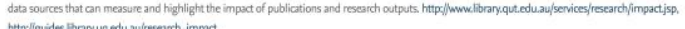

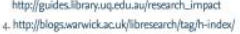

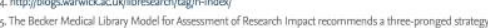

Library Connect

Subscribe for free to the Library Connect Newsletter:

Join the conversation $\mathbf{O}$ @ilibrary_connect $\mathbf{Q}$ ibraryconnect | Content by Jenny Delasalle $\mathbf{O}$ @jennyDelasalle

Fonte: Elsevier

Figura 1. Bibliotecários e tecnologia 
De acordo com (Aitken et al., 2011; Ferreira, 2014), mediar pesquisas é uma função típica dos bibliotecários de referência, quer por estarem diariamente em contato com alunos de graduação, alunos de pós-graduação, profissionais da saúde ou com qualquer outro cidadão que frequente a biblioteca, quer por terem conhecimento do acervo para investigação.

Em consequência, os autores consultados dão grande importância à entrevista para traçar o perfil do usuário e delimitar qual a sua necessidade informacional no momento da pesquisa (Brettle et al., 2007; Reis, 2013). Via de regra a necessidade se manifesta segundo os estágios da vida acadêmica. De modo geral, o aluno de graduação, no início do estudo, precisará de livros texto: um pós-graduando, precisará encontrar a base de dados mais específica; e o médico, um artigo que o ajude a encontrar o diagnóstico ou a terapia mais adequada para seu paciente naquele momento.

Seja como for, a biblioteca é o espaço em que profissionais transformam informação em conhecimento, em oportunidade de aprendizado em benefício da sociedade (Sousa, 2009).

\subsection{0 bibliotecário mediador}

O bibliotecário de referência especializa-se atualmente nos Serviços de Referência online e no uso das novas tecnologias, o que muda substancialmente seu perfil. Sempre preocupou-se com a aquisição e a classificação do material em suporte papel ou eletrônico. Hoje além dessa ocupação, organiza e dissemina a informação e o software, o que caracteriza o novo modelo de apresentação da informação. Deve ter a habilidade de localizar, avaliar e ser capaz de satisfazer as necessidades informacionais de quem busca a informação (American Library Association, 2014; Rethlefsen et al., 2014).

Ao longo do tempo, o bibliotecário recebeu várias denominações: guardião, gestor da informação, mantenedor, informacionista, bibliotecário 
acadêmico (ALA, 2014), bibliotecário médico, bibliotecário clínico e bibliotecário hospitalar; estes três últimos títulos designam o profissional que trabalha diretamente com as equipes médicas nas bibliotecas dos hospitais. As várias especialidades decorrem de o profissional, na área da saúde atualmente necessitar da informação em maior quantidade, e sempre atualizada.

Essas funções diversificadas se devem ao papel que o bibliotecário vem desempenhando na sociedade da informação em contínua mudança tecnológica. De acordo com Gomes (2009), essas mudanças introduziram nos centros de documentação e nas bibliotecas, a necessidade de mudar o perfil do bibliotecário, para desempenhar melhor suas atividades e enfrentar os novos desafios inerentes à era da informática eletrônica.

$\mathrm{Na}$ atualidade as habilidades e competências requeridas dos profissionais da informação, quer nas bibliotecas quer nos centros de documentação, estimulam-nos a inventar e adotar formas inovadoras à altura de um ambiente cada vez mais exigente. São necessárias novas habilidades e competências para permanecer na sociedade da informação do século XXI. As novas exigências são uma resposta ao fato de os usuários poderem acessar os recursos da Web sem entrar nas quatro paredes da biblioteca. Isto requer que o bibliotecário, seja competente para lidar com as ferramentas emergentes, mediante uma sólida formação em técnicas de gerenciamento de informação, habilidades relacionadas à comunicação, análise do comportamento humano e da ciência cognitiva (Singh, 2013).

Galvão e Leite (2008); Grefsheim et al. (2010); Kurup e Hersey (2007) discutem o termo informacionista, que foi usado no ano 2000, ao propor um novo profissional com as características do bibliotecário, mas ocupando um papel mais específico: o de aproximar o entendimento entre a Ciência da Informação e a pesquisa clínica. Os autores reivindicam o título de bibliotecário clínico.

Essa mediação ocorre por meio de ajudas efetivas nos diferentes bancos de dados. Portanto, o profissional que maneja a informação 
diariamente tem a capacidade de auxiliar o pesquisador que busca uma informação específica e atualizada (Galvão; Leite 2008; Sherman, 2007).

O bibliotecário, além das características próprias, ou seja, memória e desejo de servir, recebe nos anos de graduação conhecimentos de psicologia, administração, história da arte etc. Depois, ao longo do tempo, desenvolverá habilidades determinadas para exercer seu papel com características específicas.

Para Dias et al. (2004), evidente que alcançará especialização no decorrer da vida profissional, se atuar em bibliotecas ou centros de documentação, seja na área biomédica, seja em outra área do conhecimento. Já que este profissional será designado para trabalhar com a disseminação da informação junto aos diferentes públicos, deve levar em conta a formação geral e as habilidades dos indivíduos que podem ter conhecimento interdisciplinar e especializado; habilidade de comunicação interpessoal, habilidades gerenciais (criatividade, flexibilidade, otimismo, trabalho em equipe) e atualmente conhecimentos e habilidades para manusear e lidar com os sistemas automatizados.

Desse modo, Aitken et al. (2011) denominam o bibliotecário da área médica como o Bibliotecário Clínico, visto que participa ativamente das pesquisas conhecendo as bases de dados e os perfis dos médicos ou dos residentes atuantes de um determinado hospital. Assim, Bibliotecário Clínico fornece pesquisas imediatas: literatura, e orientação individual para o uso dos recursos baseados em evidências, bem como técnicas de pesquisa e de medicamentos. A intervenção teve um efeito positivo sobre os médicos: foram fornecidos a eles artigos para apoiar decisões de atendimento ao paciente, com base no suporte de pesquisa mediada pelo Bibliotecário Clínico.

\subsection{Sociedade da Informação}

A sociedade passou primeiro pela mudança de atividade agrícola para industrial e desta para informacional na qual, a informação e o conhecimento 
começaram a constar do planejamento estratégico das organizações em busca de mudanças, tornando-se elementos importantes para manter o nível de competitividade. Estes elementos estão cada vez mais embutidos nos produtos do nosso cotidiano (Duarte et al., 2007).

Do latim informatio informação significa etimologicamente, representação da ideia pela palavra. Atualmente é o recurso mais importante que um indivíduo ou uma organização utilizam para determinar as metas que desejam alcançar. É o fator determinante do crescimento e inovação de uma instituição. De seu uso adequado, sua recuperação e disseminação, dependerá o nível de conhecimento da empresa ou indivíduo.

Da apropriação da informação, por sua vez, depende o grau de competência, e aperfeiçoamento que o médico pode alcançar. Para além do perfil adequado à profissão, do bom relacionamento com os pacientes e do contínuo diálogo com os seus pares, o profissional eficiente deve estar atualizado quanto às recentes pesquisas em sua área de atuação (Souza, 2010; Aun, 2014). E após os anos de graduação, para se manter atuante, para continuar o diálogo com seus pares e, principalmente, ser eficaz em suas tarefas, isto é, no atendimento ao paciente, precisa de uma larga variedade de informação. Nos dias atuais ser um médico eficiente significa ser um contínuo pesquisador.

Segundo Marteleto (2007), a informação é um elemento da cultura (criação humana) que carrega sentido a ser comunicado para produzir conhecimento.

$\mathrm{Na}$ sociedade da informação o desenvolvimento de conhecimentos, habilidades e atitudes para lidar com a informação é requisito imprescindível para o sucesso dos indivíduos, não apenas no contexto acadêmico, mas ao longo da vida, o que está em consonância com o conceito de competência em informação. O bibliotecário, como profissional capacitado para uso da informação com efetividade, necessita atentar nessa demanda decorrente da sociedade atual e atuar como agente educacional no desenvolvimento dessas competências (Felício, 2014). 
Pires (2011) distingue dados, informação e conhecimento, uma vez que se confundem, em decorrência da proximidade de seus significados. Para ele, dado é um atributo descritivo, qualitativo ou quantitativo acerca de um objeto ou de um fato. É um item elementar da informação que, por sua vez, corresponde a um conjunto de dados estruturados ou descritivos, que tem significado em um contexto. A transformação de dados em informação costuma ser realizada de uma forma compreensível ao usuário. Conhecimento, segundo ele, designa a compreensão por parte de um indivíduo em um domínio específico.

Com a informação encontrada na Web, estima-se existir um bilhão de páginas em html e diversas ferramentas disponíveis para recuperá-la, mas ao procurá-la, o usuário tem grande quantidade de informação e nem sempre de relevância (Cendón, 2001). Não queremos aqui tirar a importância dos meios de que se dispõe para chegar à informação, é melhor ter essa gama do que não a ter, no entanto, é necessária a ajuda de um profissional da informação capaz de recuperar artigos com maior exatidão relativamente aos objetivos do pesquisador.

O processo da gestão da informação abrange toda a forma de gerar, armazenar, distribuir e utilizar a informação, tornando necessária a capacidade de gerir tecnologias de informação para facilitar o processo, devido ao grande e contínuo acúmulo no volume de dados (Cardoso; Machado, 2008).

O acesso à informação consiste nas diversas possibilidades de chegar aos recursos informacionais, podendo ser físico ou virtual. O acesso virtual dáse habitualmente por meio de e-mail ou envio do próprio documento online, uma vez que as bases de dados no primeiro momento apresentam apenas resumos.

A informação como tomada de decisão é a base e o suporte de toda ação que busca excelência, e o profissional da saúde para ser capaz de realizar com eficiência os deveres diretamente relacionados ao cuidado do paciente deve reciclar continuamente seus conhecimentos o que pressupõe atualizar-se. A competência virá com a capacidade de executar os deveres de uma profissão em geral ou cumprir uma tarefa profissional especial com 
habilidade de qualidade aceitável, tanto para o mediador quanto para 0 profissional que busca a informação.

O crescimento da informação e a busca incessante de conhecimento do pesquisador determinaram a necessidade de um profissional para mediar o processo. Segundo Souto (2008), outras vezes, o mediador por meio de interação com o pesquisador e o acompanhamento sistematizado dos usuários, participa do processo de busca de informação não apenas em relação à identificação dos dados mas também no curso de apropriação deles.

\subsection{Descritores}

Os descritores são termos adotados de um vocabulário estruturado, utilizado na indexação (análise de conteúdo) e na fonte do documento para o ingresso na base de dados de todos os registros bibliográficos dos artigos publicados em revistas indexadas em bases de dados. Deste modo, esse recurso ou ferramenta facilita a recuperação da informação. Cada base de dados utiliza um vocabulário controlado e existe um distinto para quase todas as áreas do conhecimento (Cardoso, 2009).

Trata-se de termos de grande valor para a indexação, pois muitos pesquisadores da área da saúde, usam-nos para delimitar um campo da ciência, utilizam-nos na busca de informações para pesquisar sobre doenças, técnicas cirúrgicas ou mesmo para escrever um trabalho (Brandau et al., 2005).

O uso de descritores, por exemplo, facilitaria essa busca com menos tempo de pesquisa. $O$ recurso funciona como filtro, que limita a quantidade, ao mesmo tempo que aumenta a exatidão. Além dos descritores é necessário escolher a base de dados conveniente.

Por meio dos descritores, o bibliotecário potencializa o tempo e a eficácia da pesquisa. O ideal seria que ao menos no início de sua pesquisa, o pesquisador procurasse um profissional de referência para determinar os descritores da sua área de atuação. Recomenda-se que recorra a esses 
termos, para que possa recuperar a informação com menos tempo de pesquisa.

\subsection{Information needs}

A expressão: information needs aparece nas várias bases de dados desde o século passado, no entanto na última década tem aparecido com maior frequência, devido ao aumento explosivo da literatura, e também substitui o termo "estudo de usuário".

A definição filosófica, para a expressão necessidade de informação é apresentada por Ford e Korjonen (2012), a partir de dois ângulos: no primeiro, corresponde a tomada de decisão de um indivíduo, ao enfrentar uma incerteza, que demanda um estímulo ou parte de uma informação, para sanar a dúvida; e no segundo, a expressão significa que o indivíduo deve ser equipado para reconhecer a existência de sua incerteza. Simplificando, necessidade de informação pode ser definida como a exigência de um pedaço de informação por um indivíduo, de modo a realizar uma tarefa: o indivíduo pode ou não estar ciente de que necessita, deste pedaço de informação, mas a necessidade ainda existe. Diz-se pedaço da informação, porque ninguém se apropiará da informação em sentido absoluto, mas apenas de parte dela devido a limitação do conhecimento.

Para Rodrigues e Crippa (2011), o leitor ao se deparar com informações que the possam ser importantes, e que respondam às suas necessidades informacionais, isto é, o que lhe é proeminente. Para facilitar o acesso a esta informação completa, e reduzir o tempo de busca dos usuários, profissionais da área com ajuda de outros das áreas de linguística e semântica, constroem instrumentos chamados thesaurus. Estes instrumentos reúnem termos que são retirados da linguagem natural e transformados em descritores.

A pesquisa biomédica e clínica tem experimentado uma evolução considerável nos últimos anos. Grandes avanços tecnológicos em pesquisa 
básica e assistência médica, combinados com as influências crescentes da medicina e da ciência em geral, têm desafiado o modelo de suporte tradicional da biblioteca. Novos caminhos se abrem para que os profissionais da informação possam articular a respectiva capacidade de gerar dados com as necessidades informacionais dos pesquisadores (Cleveland et al., 2012).

Segundo Giddens (2002), estamos presenciando desde há vinte anos, uma intensa e radical transformação tecnológica, que tem proporcionado um crescimento acentuado do acesso à informação. Para que este acesso seja rápido e feito de forma ordenada, é necessário o uso de instrumentos e ferramentas da área específica dentro da qual se busca o conhecimento.

Identificar as necessidades de informação é o primeiro passo do processo. Essa etapa se traduz no conhecimento do ambiente em que a informação é usada, considerando os usuários que interagem com a organização na busca da informação (Reis, 2013).

Para Garbin et al. (2008), o mundo presenciou nos últimos anos uma ampla transformação tecnológica que aumentou substancialmente o acesso à informação. $\mathrm{Na}$ área da saúde, há cada vez mais informação disponível, sendo importante a presença do profissional que a dissemine. Com o uso crescente da tecnologia, o novo profissional tende a desenvolver as habilidades tecnológicas e a respectiva criatividade, para contribuir no processo de dinamização do trabalho na área da saúde (Guevara, 2007; Partridge et al., 2010).

Segundo Curran et al. (2010), há um maior número de médicos usa a Internet para buscar e localizar informações, o que faz da respectiva ferramenta imprescindível para o desenvolvimento profissional. Programas de treinamento presencial ou à distância, constituem uma abordagem cada vez mais popular para a educação médica. A Internet tem se expandido em oportunidades para o fornecimento de uma forma mais flexível, conveniente e adequada à realidade de conhecimento que parece ter cumprido o papel de ajudar profissionais ocupados que não têm tempo de participar das sessões formais de educação. 
As necessidades informacionais variam de grupo para grupo e as buscas nas fontes primárias (livros-textos), ou nos bancos de dados podem se tornar complexas. Para Martínez-Silveira (2005), as características que influenciam as necessidades informacionais dos médicos-residentes estão relacionadas ao fato de se encontrarem em um momento crítico de sua formação de especialistas, em que o objetivo da prática profissional é principalmente a aprendizagem.

\subsubsection{Alunos de graduação: medicina e para-médicos}

Os alunos de graduação em Medicina, Fisioterapia, Terapia Ocupacional e Fonoaudiologia, procuram diretamente pelos livros textos, sendo o suficiente um banner para indicar a localização dos livros organizados nas prateleiras de acordo com as diversas especialidades da área médica. Além dos livros impressos, atualmente, os alunos de graduação contam com tablets para fazer uso dos e-books. É necessário estar em contato com as sugestões dos alunos e professores para encontrar no mercado editoras que forneçam novas publicações e manter o acervo atualizado.

O advento das diversas ferramentas de acesso à Web, tais como mobile tablet device tem facilitado a busca da informação e transformado este cenário. Desse modo, mesmo fora de um ambiente normal: casa, biblioteca, o indivíduo acessa a informação mudando o comportamento antes conhecido como consumidor de informação, passa a construir e escrever a história da informação digital.

A Biblioteca Interativa da DBD/FMUSP - criada em fevereiro de 2013, após estudos e verificação nas Bibliotecas das Universidades de Harvard e Stanford, conta com as ferramentas mais recentes da área médica. Foram disponibilizados tablets com a coleção completa de livros eletrônicos da editora Ateneu especializada em medicina. São quatro salas equipadas para estudo dos alunos de graduação que contam também com equipamentos modernos para vídeo-conferência. 
Nos treinamentos são exercitados no uso das bases de dados, mas chegam a concretizar pesquisas bibliográficas a partir do $4^{\circ}$ ano, quando começam as práticas médicas ou a Iniciação Científica.

Há ainda o ensino à distância para os alunos de graduação em Medicina. Iniciado em 2008, para facilitar o aprendizado da pesquisa biomédica, o curso oferece ao aluno de graduação disponibilidade de fazer o curso na hora em que Ihe for mais conveniente. Com o objetivo de:

Capacitar o aluno para identificação e recuperação da informação de documentos, impressos e eletrônicos, que tratem da prática médica, nos seus diversos aspectos: será dada ênfase para a atribuição de pertinência e relevância dos resultados obtidos, no intuito de estimular a busca pela qualidade científica das informações recuperadas. Será utilizado ambiente virtual de aprendizagem (Curso EAD, 2013).

\subsubsection{Pós-graduandos}

Para esta dissertação, levou-se em conta o comportamento dos pósgraduandos Strictu senso (mestrado/doutorado), os médicos e outros profissionais da saúde, que diariamente, buscam as fontes de informação na área da saúde na Divisão de Biblioteca e Documentação da Faculdade de Medicina da Universidade de São Paulo.

Desde a década de 1990, a DBD/FMUSP atende profissionais pósgraduandos para a realização da ficha catalográfica. Ao prestar este serviço, realizado em conjunto com a Comissão de Pós-Graduação da Faculdade de Medicina da Universidade de São Paulo (CPG/FMUSP), o bibliotecário auxilia a normalizar dissertação/tese, na escolha dos descritores possibilitando a respectiva inserção dos trabalhos nas bases de dados nacionais e internacionais. Uma vez normalizados, os trabalhos são inseridos na Biblioteca Digital de Teses e Dissertações - BDTD, com visibilidade mundial, uma vez que esta base de dados está em quatro idiomas: português, inglês, francês e espanhol. 
Há ainda na BDTD, um espaço em que o pós-graduando poderá inserir trabalhos decorrentes a este. Há sem dúvida uma renovação no conhecimento e com essa visibilidade global ele contribuirá com 0 conhecimento ao mesmo tempo que seu trabalho é difundido.

Se preferir o pós-graduando pode participar de treinamentos e cursos ministrados pela Biblioteca. Há dois tipos de treinamentos. O informal que é dado quando ele comparece na Biblioteca e é auxiliado na escolha dos descritores, na estratégia de busca, na escolha da base de dados mais específica ou ainda a conseguir o artigo completo. $O$ treinamento formal é dado pelo Programa de Moléstias Infecciosas e Parasitárias com a disciplina MIP5722 Pesquisa Bibliográfica Automatizada em Bases de Dados de Medicina Clínica e Especializada em Doenças Infecciosas e Parasitárias, ministrada anualmente e valendo três créditos.

Para maior acessoramento, o aluno de pós-graduação tem uma área na home page da Biblioteca, com material e aconselhamento para facilitar o desenvolvimento do trabalho. Há ainda o Guia de Apresentação de Dissertações, Teses e Monografias editado desde 1993, primeiramente impresso e atualmente online.

\subsection{Informação e conhecimento}

Para Sousa (2009) e Singh (2013), informação e conhecimento, são conceitos extremamente ligados e normalmente de difícil distinção. Há grande consenso entre diversos autores de que a informação pode ser de qualquer tipo de dado que, recebido pelo indivíduo, responda a uma demanda específica e uma vez assimilada por ele, é capaz de alterar o status do conhecimento.

Nas sociedades pós-industriais, ocupa lugar central a informação transformada em conhecimento. Emergem, assim, no âmbito da produção e das instituições, novas formas de trabalho, entre elas o trabalho intelectual, 0 trabalho interativo, o trabalho comunicacional (Libâneo, 2003). Essas 
transformações atingem em cheio as escolas, as pesquisas dos bibliotecários e dos pesquisadores.

Sociedade da informação e do conhecimento, este novo modelo de organização das sociedades assenta num modo de desenvolvimento social e econômico no qual a informação, como meio de criação de conhecimento, desempenha um papel fundamental na produção de riqueza e na contribuição para o bem-estar e qualidade de vida dos cidadãos (Reis, 2013).

Para Duarte et al. (2007), conhecimento é a informação com valor agregado, elemento habilitador da decisão, é tudo que deve ser conhecido, antecipadamente, para iniciar o curso de uma ação. A informação acessada pela Internet, com as mais recentes ferramentas, pode gerar conhecimento que se torna algo tangível como por exemplo: livro, tese ou artigo.

A informação transformada em conhecimento é elemento essencial ao desenvolvimento de uma organização, mais ainda em se tratando de uso de recurso que pode propiciar a melhora de um paciente ou facilitar a comunicação entre os pesquisadores envolvidos em um mesmo projeto.

Há um desenvolvimento substancial na qualidade das pesquisas realizadas. Percebe-se, portanto, a necessidade de atuação do profissional da informação nesse contexto, tendo em vista que o bibliotecário pode interferir no modo como os pesquisadores trabalham a informação, contribuindo para suprir parcial ou plenamente uma determinada necessidade informacional (Almeida Júnior, 2009; Valentim; Cavalcante, 2011).

Para Xavier e Costa (2010), a informação e o conhecimento são simultaneamente causa e efeito de si mesmos, numa interação dinâmica em que a sucessão pode ser plenamente invertida, mas não gera contradição. Disponibilizar informação é promover a geração de conhecimento que, por sua vez, produzirá mais informação e assim sucessivamente.

Portanto, é necessário ter em mente, segundo os autores, que a informação científica que se oferece, não carrega em si a simples função de informar uma inovação, mas detém a potencialidade de produzir conhecimento. 
Corroborando a importância do bibliotecário, o autor volta a afirmar que é necessário levar em conta que a informação científica não tem apenas a função de inovar, mas que possui a potencialidade latente de produzir conhecimento. Contudo, esse potencial só pode ser ativado por um indivíduo capaz de colocar em exercício sua capacidade no momento de assimilação da informação, isso se faz possível quando conhece bem o perfil de seu cliente e o acervo que tem acesso (Burford; Park, 2014).

Assim, para Carvalho (2004), não há receita mágica, somente a informação construída, reelaborada, apropriada se transforma em conhecimento.

A Figura 2 traduz visualmente o que na realidade acontece, quando um conjunto de dados acumulados na Web, com a mediação de um profissional da informação, se transforma em conhecimento.

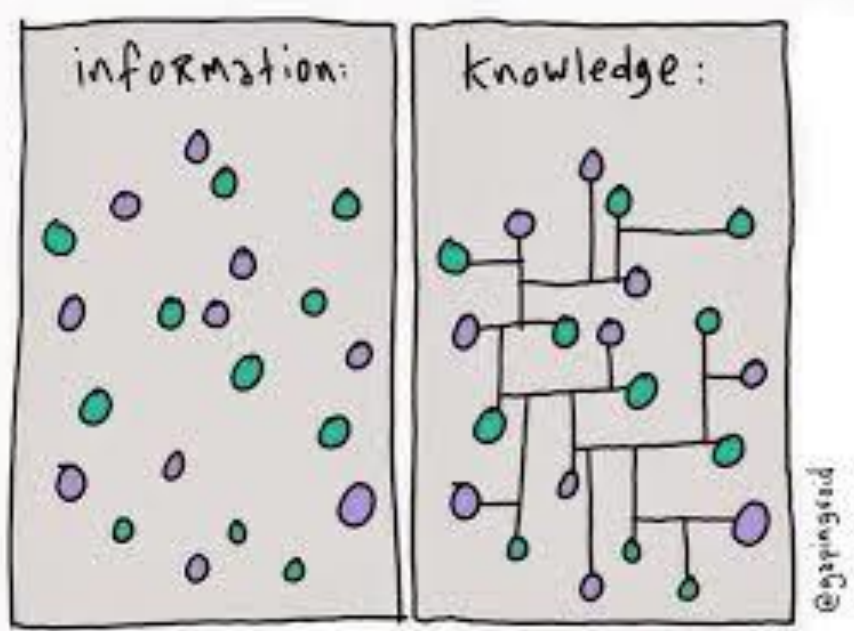

Fonte:https://www.google.com.br/search?q=informa\%C3\%A7\%C3\%A30+e+conhecimento\&biw=.

Figura 2. Informação vs conhecimento 


\subsection{Competência}

Competência clínica ou habilidade clínica é a capacidade de realizar aceitavelmente aqueles deveres diretamente relacionados ao cuidado do paciente (BIREME, 2014).

Competência é saber agregar informação. Transformar conhecimento em atitude tanto nas tarefas corriqueiras, quanto em grandes tarefas. É saber transferir conhecimento, ter iniciativas, inovar e interagir com os demais membros da equipe.

Na Aula Inaugural do Curso de Graduação de Medicina da FMUSP, se apresentou o termo competência em sete itens ou degraus ${ }^{1}$ :

* I. Atenção à saúde;

II. Tomada de decisão;

III. Comunicação

IV. Liderança;

V. Administração e gerenciamento: princípios e valores;

VI. Educação continuada;

VII. Profissionalismo: ética e compromisso com os valores sociais.

O acesso à informação deve proporcionar ao profissional o conhecimento para ter a capacidade de resolver problemas e até antecipar-se a eles, com suas atitudes e decisões inovadoras. Com o avanço tecnológico e a gama de informações de que dispõe, o profissional competente saberá relacionar-se com a equipe motivando-a a alcançar seus objetivos.

Para Cardoso e Machado (2008), a informação é a base e o suporte de toda ação em que se busca excelência, crescimento, transformação e inovação. Atualmente há informação em grande quantidade na Web, mas é

\footnotetext{
${ }^{1}$ Anotações da aula inaugural na FMUSP da Profa. Dra. Maria do Patrocínio Tenório Nunes em 24 de fevereiro de 2014.
} 
preciso que seja encontrada de modo rápido e em curto prazo. Ora, como já destacamos, o acesso adequado e eficaz à informação tem o potencial de gerar conhecimento, o que leva à competência, uma vez que na sociedade atual da informação se necessita de atitudes inovadoras.

Zarifian (2003) destaca que competência é a tomada de responsabilidade de um indivíduo ou grupo sobre uma situação profissional. É ter autonomia para assumir responsabilidades frente a situações profissionais complexas, mediante a reflexão sistemática diante de circunstâncias de trabalho variáveis e parcialmente imprevistas. Isso pressupõe uma inteligência prática a respeito das situações, a qual se apoia em conhecimentos adquiridos, e os transforma à medida que aumentam as dificuldades inerentes às situações. Além disso, pela competência, o indivíduo mobiliza mais pessoas em torno dessas situações, compartilha desafios e assume a parcela de responsabilidade adequada às circunstâncias e de acordo com o seu conhecimento e prática.

Fica patente, assim, a importância da informação e da educação para Zarifian (2003), a ponto de ele enfatizar que o momento em que vivemos é o "século do conhecimento". Quanto mais qualificado, for um indivíduo, mais autônomo será em seu trabalho e, por consequência, mais responsável. Essa complexidade, tão diversa da realidade vigente até então, mostra que as transformações oriundas dos conhecimentos serão cada vez mais extensas e mais rápidas, interligadas e imprevisíveis.

Com essa perspectiva, Fleury MTL e Fleury A (2001) resumiam o conceito de competência da década de 80 como um conjunto de conhecimentos, habilidades e atitudes, isto é, um conjunto de capacidades humanas que justificam um alto desempenho, sendo que os desempenhos mais bem avaliados se apoiam na inteligência e na personalidade dos indivíduos. A competência passa então a ser percebida como uma bagagem de recursos que o indivíduo possui.

Segundo os mesmos autores, a aquisição de conhecimentos e o desenvolvimento de competências se dão por processos pró-ativos ou por 
processos reativos. Os processos pró-ativos constituiriam a experimentação e a inovação, responsáveis pela geração de novos conhecimentos e metodologias, de novos produtos ou serviços, com base em situações não rotineiras. Os processos reativos se explicariam pela resolução sistemática de problemas, experiências realizadas por outros e contratação de pessoas. Enfim, a competência se forjaria com a novidade e a complexidade.

Nobre (2005) utiliza a palavra competência para definir a capacidade de um indivíduo para exercer uma atividade com eficiência, atingindo os objetivos propostos. Por outro lado, o oposto da competência significa para a sociedade sempre algo negativo, depreciador, chegando mesmo o autor a sinalizar que a pessoa se encontra ou se encontrará brevemente marginalizada dos circuitos de trabalho e de reconhecimento.

Além disso, o bom profissional incorpora competências, ou aperfeiçoa as que possui, de acordo com a sua vivência no ambiente de trabalho. Pessoas altamente capacitadas estão constantemente modificando competências e adquirindo novas formas de agir, de pensar e de se posicionar em sua atividade profissional, de forma a serem vistas como aptas para promover a sua respectiva instituição (Zarifian, 2003).

Para Gasque (2011), competência refere-se ao uso da informação que inclui atividades em que o indivíduo se engaja em um movimento que transformará esta informação em conhecimento. Abrange ainda, habilidades intelectuais como decodificação e interpretação, controle e organização do conhecimento por meio do uso de instrumentos cognitivos como resumos, esquemas, mapas conceituais e textos. Buscar e usar a informação são processos que abrangem também valores pessoais, motivações, crenças, visão crítica e atitudes como responsabilidade e ética. A busca e o uso da informação envolvem ainda a capacidade do indivíduo de refletir suas fontes; usar a informação ética e legalmente para atingir os objetivos específicos.

Para isso o profissional precisará de informação e para ter acesso a essa informação, poderá contar com outro profissional capaz de disseminá-la, 
para que nada se perca ou mais ainda, ela seja encontrada com rapidez, precisão e relevância.

Como verificamos no dia-a-dia da nossa prestação de serviço na DBD/FMUSP, pesquisador e profissionais da área da saúde, buscam a informação mais recente, por exemplo, procuram um artigo sobre uma patologia ou resultado de tratamento relatado em um periódico que foi citado em alguma entrevista ou em grupo de estudo, aula, conferência etc. ou ainda perante um paciente que se encontra na mesa de cirurgia, e para o qual se busca um diagnóstico. Há ainda o usuário movido simplesmente pelo prazer de ler alguma coisa atualizada sobre sua especialidade. 


\section{OBJETIVOS}


Traçar o perfil dos usuários da Biblioteca da FMUSP em 2012 e detectar possíveis influencias na mudança de hábitos destes usuários quando submetidos a mediação informal (orientação) pelo bibliotecário.

Pesquisar a literatura corrente sobre a mediação do profissional da informação, mais especificamente sobre a qualificação do bibliotecário como mediador entre aquele que pesquisa e as ferramentas tecnológicas que propiciam um acesso eficiente às informações. 


\section{MÉTODOS}


Essa pesquisa foi aprovada pelo Comitê de Ética para Análise de Projetos e Pesquisa (CAPPesq) do Hospital das Clínicas da Faculdade de Medicina da Universidade de São Paulo sob número 438/11, em 07 de outubro de 2011 (Anexo A).

Trata-se de um estudo exploratório que buscou, através de um questionário baseado no perfil dos usuários do Serviço de Atendimento e Informação (SAI) da DBD/FMUSP, demonstrar a influência da mediação do bibliotecário em vários níveis, dependendo das necessidades informacionais do usuário. Entenda-se por mediação neste caso, qualquer auxílio ou orientação prestados pelo bibliotecário durante a presença do usuário na biblioteca ou mesmo por via remota, por e-mail ou telefone.

Para melhor compreensão e aplicabilidade desse trabalho, descrevemos a seguir os passos adotados.

\subsection{Amostra}

Foram convidados a participar do estudo 419 pós-graduandos atendidos no SAI da DBD/FMUSP em 2012, que compareceram à biblioteca a fim de solicitar a ficha catalográfica da dissertação/tese e indexação dos termos que identificam a pesquisa, utilizando as ferramentas pertinentes e normatizando seu trabalho com as normas da Faculdade.

Também participaram desta amostra os 151 profissionais da saúde, na maioria médicos, que diariamente procuram o SAI/FMUSP, pessoalmente ou por e-mails, para realizar suas pesquisas ou acessar os artigos completos.

\subsection{Questionário}

O questionário é a forma mais usada para coletar dados, pois possibilita medir com mais exatidão o que se deseja (Cervo; Bervian, 2007). 
Constitui um meio de obter respostas a questionamentos que seguem uma lógica subordinada ao problema que se propõe resolver. Pode-se apresentar de duas formas: impresso ou eletrônico.

Preferimos o formato eletrônico, pois facilitaria a participação de um número maior de respondentes bem como a brevidade em recebê-los de volta.

A preparação do questionário baseou-se nos perfis dos pesquisadores e pós-graduandos que frequentam a biblioteca. Composto de 10 perguntas abertas, e de múltipla escolha, tentou-se avaliar se os pesquisadores participaram de algum treinamento, usam descritores para facilitar suas buscas.

O questionário foi enviado no período de 12 de dezembro de 2012 a 30 de abril de 2013.

Foi solicitada anuência à direção da Biblioteca para aplicar este questionário (Anexo B).

\subsection{Critérios de inclusão}

$>$ Alunos de pós-graduação Strictu sensu matriculados nos Programas de Pós-graduação da FMUSP, que solicitaram a ficha catalográfica para normalização, indexação e inclusão de seus trabalhos nos bancos de dados;

> Médicos e outros profissionais da área da saúde do Hospital das Clínicas/FMUSP, que frequentaram a Biblioteca em 2012.

\subsection{Análise dos dados}

Os dados foram transferidos para planilhas do Microsoft Excel para ordenação, classificação e análise preliminar e posteriormente foram analisados com auxílio do software SPSS 17.0. Foram utilizados testes de 
associação de Chi quadrado ou teste exato de Fischer, conforme as divisões da amostra resultassem em tabelas de contingência dos tipos 2x3 (para aquelas perguntas com três opções de resposta) ou 2x2 (quando eram apenas duas as opções de resposta). Estes testes foram apresentados com os valores dos Riscos Relativos com seus respectivos intervalos de confiança ao nível de 95\% e valores de p (com nível de significância de 5\%). 


\section{RESULTADOS}


Dos 570 questionários enviados, 247 foram devolvidos entre o mês de dezembro de 2012 e abril de 2013. Ou seja, aproximadamente 43\% responderam ao questionário.

Foi escolhido o modo eletrônico, podendo assim chegar a um número maior de pessoas, pois muitos usuários fazem o contato com a Biblioteca por e-mail.

\subsection{Caracterização da população}

O questionário foi preenchido por 247 pessoas. Dentre elas, a maioria é do sexo feminino (153) e tem entre 30 e 39 anos, como podemos observar nos Gráficos 1, 2 e 2.1. Além disso, mais da maioria dos respondentes são médicos (Tabela 1). As seguintes ocupações também foram observadas: Assistente social, Docente-História, Docente-Educação, Enfermeiro, Farmácia, Nutricionista, Pedagoga, Pediatra, Saúde Ambiental, Terapeuta Ocupacional e Veterinário (Gráfico 3). No Gráfico 4 os usuários que participaram da pesquisa estão distribuídos em médicos e não-médicos conforme o gênero.

Gráfico 1. Sexo dos respondentes

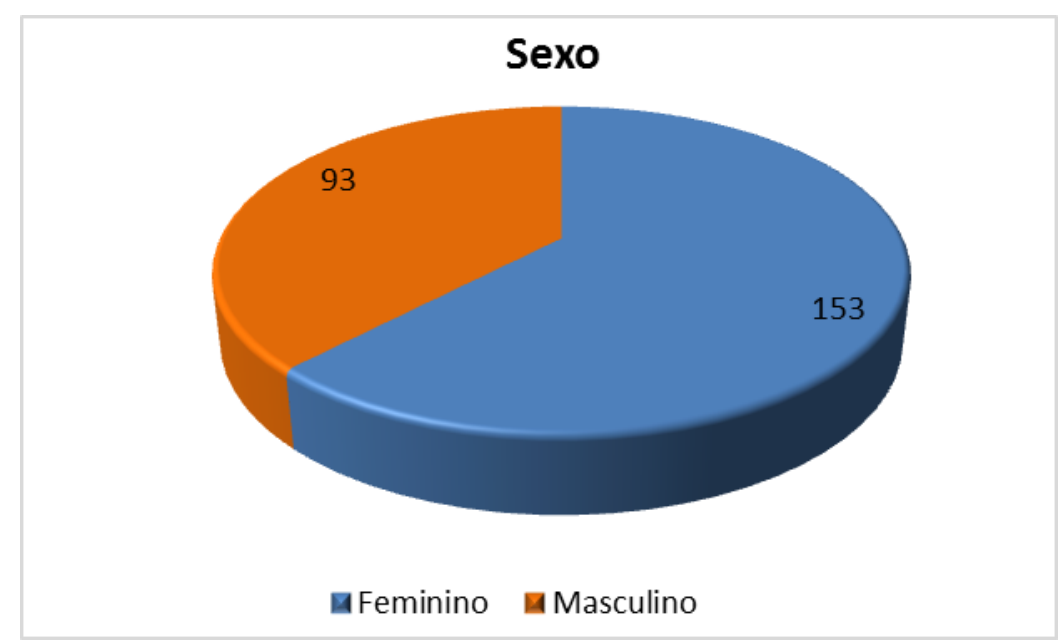


Gráfico 2. Idade dos respondentes

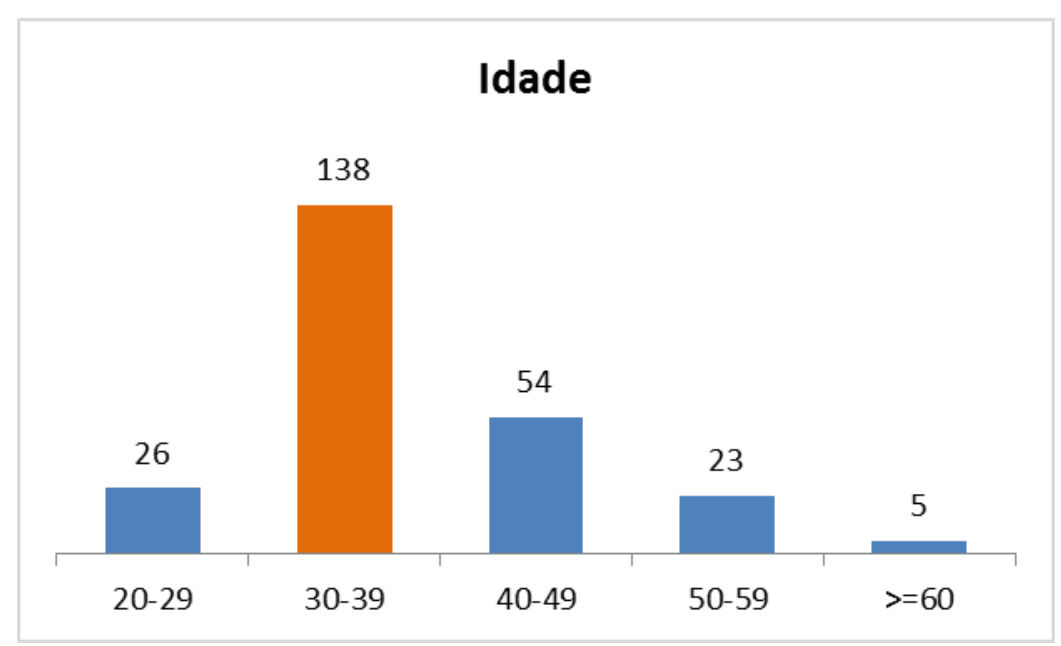

Gráfico 2.1. Idade dos respondentes separada por sexo

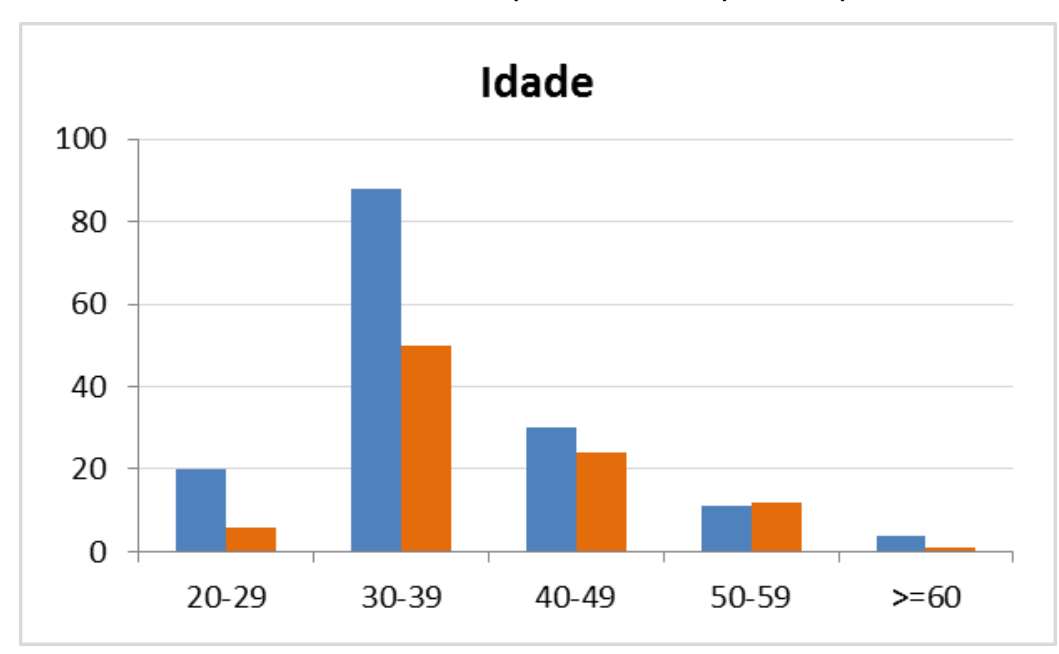

Tabela 1: Distribuição de sexo e profissão da população estudada

\begin{tabular}{cc|c|c|c}
\hline \multirow{2}{*}{} & \multicolumn{2}{|c|}{ Profissão } & \\
\cline { 3 - 5 } & Não-médico & Médico & Total \\
\hline \multirow{2}{*}{ Sexo } & Masculino & 24 & 69 & 93 \\
\cline { 3 - 5 } & Feminino & 94 & 59 & 153 \\
& Total & 118 & 128 & 246 \\
\hline
\end{tabular}


Gráfico 3. Distribuição da população deste estudo de acordo com a profissão

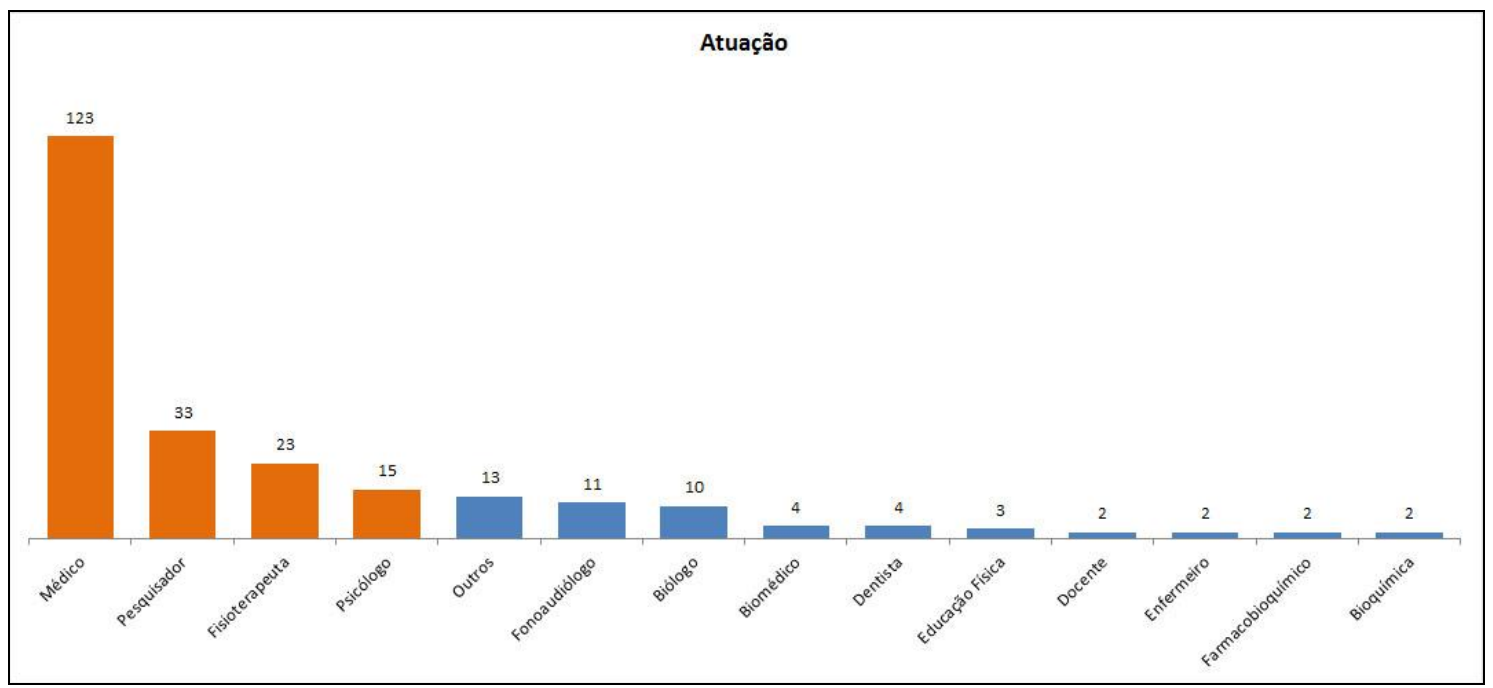

Gráfico 4. Atuação dos respondentes de acordo com o sexo

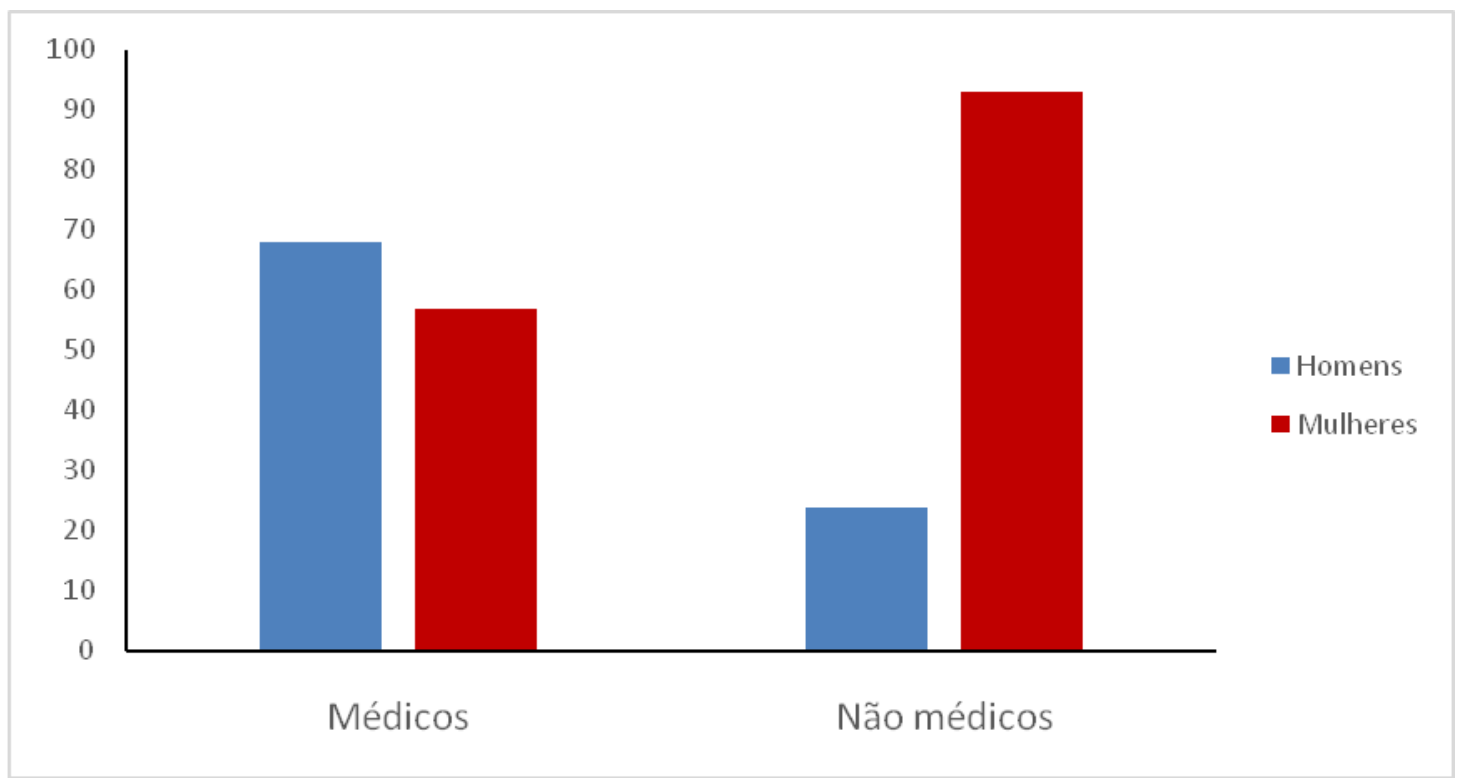

Observamos que, aproximadamente, 80\% desta população acessa as informações referentes à sua área com uma frequência maior, ou seja, diariamente ou semanalmente (Gráfico 5). 
Gráfico 5. Frequência de utilização das bases de dados

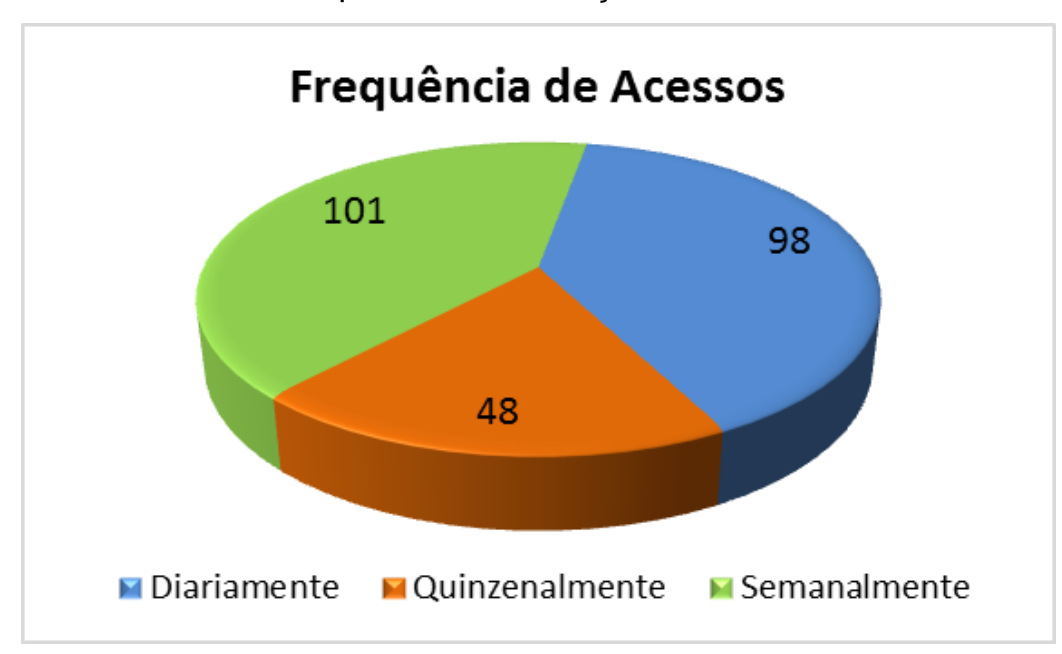

Mais de $95 \%$ dos respondentes atualiza-se por meio das bases de dados, sendo esta a fonte de pesquisa mais utilizada (Gráfico 6).

Gráfico 6. Fontes de pesquisa utilizadas

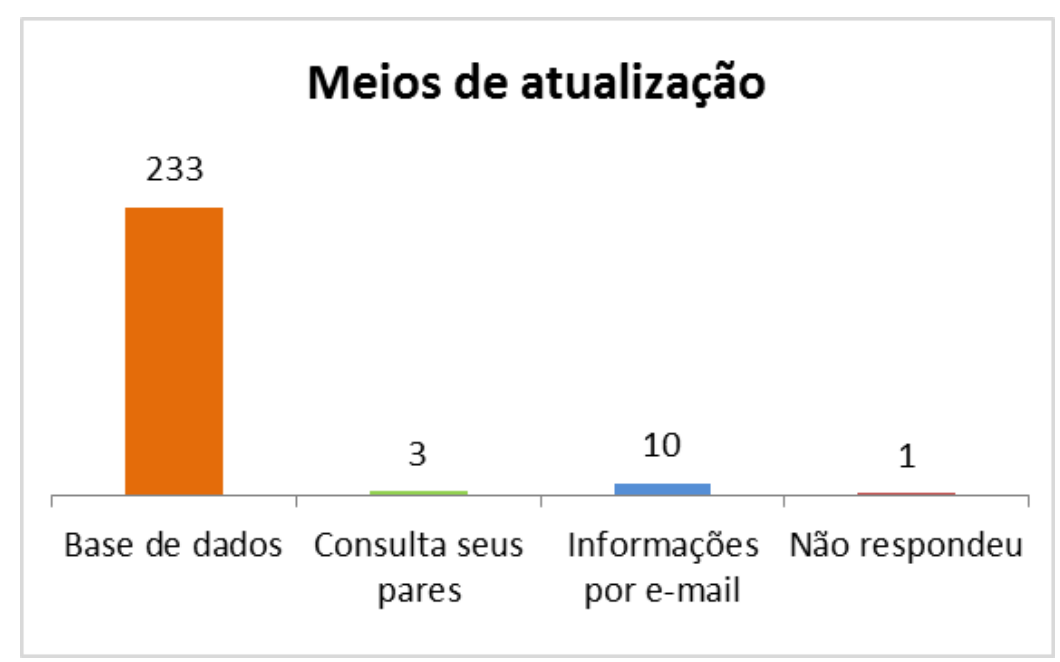

A base de dados mais utilizada é a Medline. Porém, mais de $27 \%$ utiliza todas as bases de dados (Google Scholar, Lilacs, Medline, Scopus, dentre outras) (Gráfico 7). 
Gráfico 7. Bases de dados utilizadas

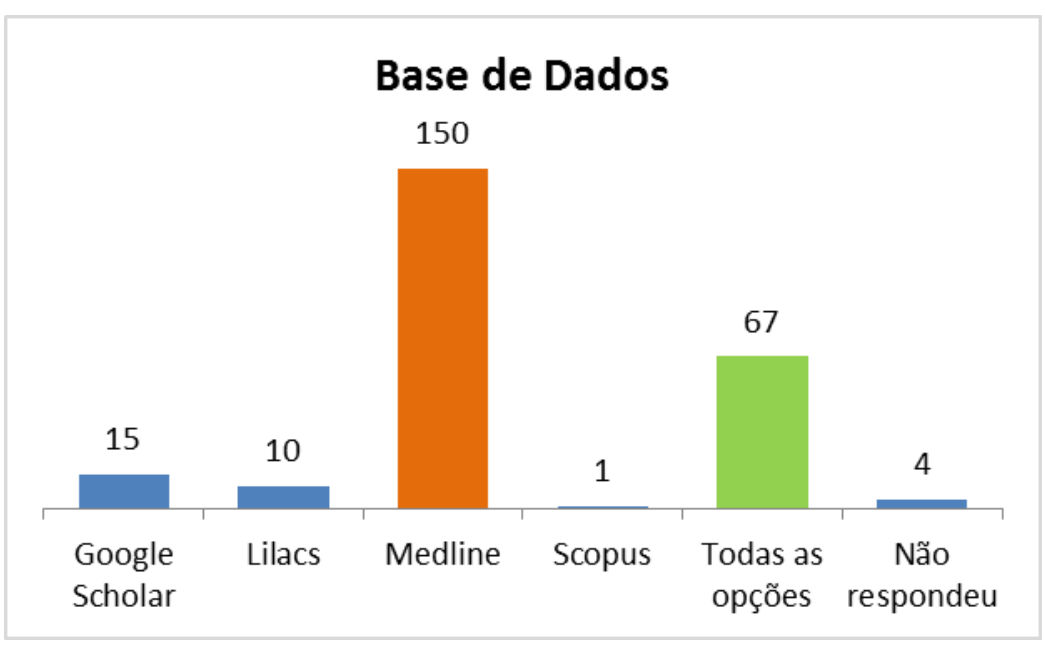

Ao questionamento sobre o uso de resumo ser suficiente nas pesquisas, 215 (quase 90\%) responderam que não, e 32 responderam que sim. De modo geral, os pesquisadores concordaram que só os resumos não são suficientes para a informação ser transformada em conhecimento, sendo necessário acessar o artigo completo (Gráfico 8).

Gráfico 8. Utilização de resumos

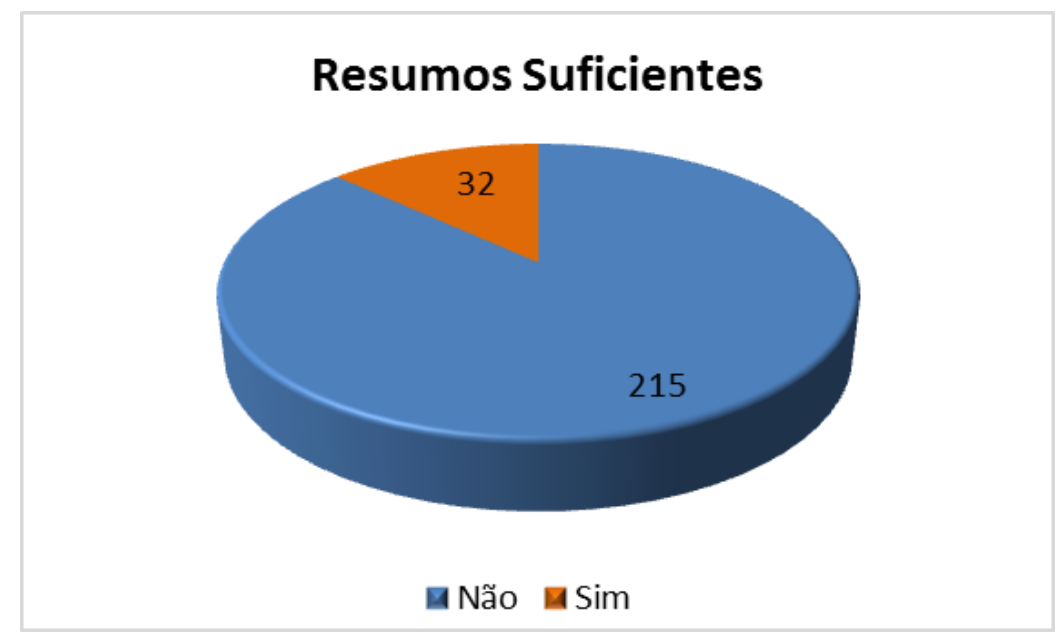

Com relação a obter 0 artigo completo, 70 responderam que conseguiram por meio da Biblioteca e 177 por meio de periódicos online (Gráfico 9), evidenciando, também, a inserção da internet e da tecnologia nas pesquisas e na obtenção de conhecimento. Os pós-graduandos enquanto 
matriculados nos Programas de Pós-graduação, tem acesso aos artigos completos através da conexão VPN (Virtual Private Network).

Gráfico 9. Meios para busca do artigo completo

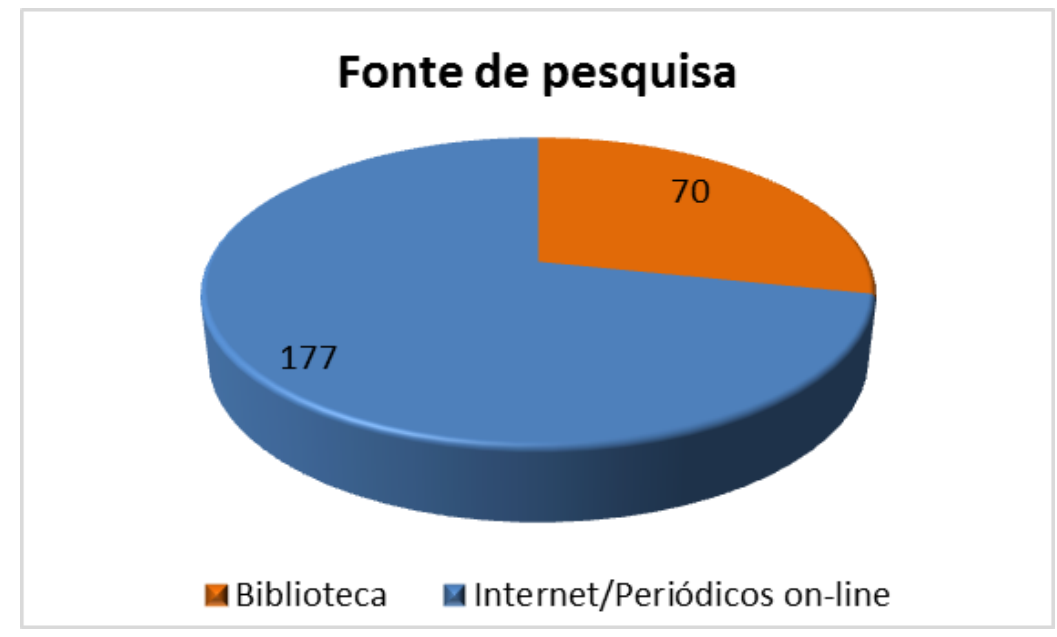

Por meio do Gráfico 10, podemos observar que $87 \%$ dos respondentes utilizaram descritores (215 pessoas). Isso demonstra que tiveram contato com o bibliotecário, o qual auxiliou no uso desta ferramenta.

Gráfico 9. Uso de descritores

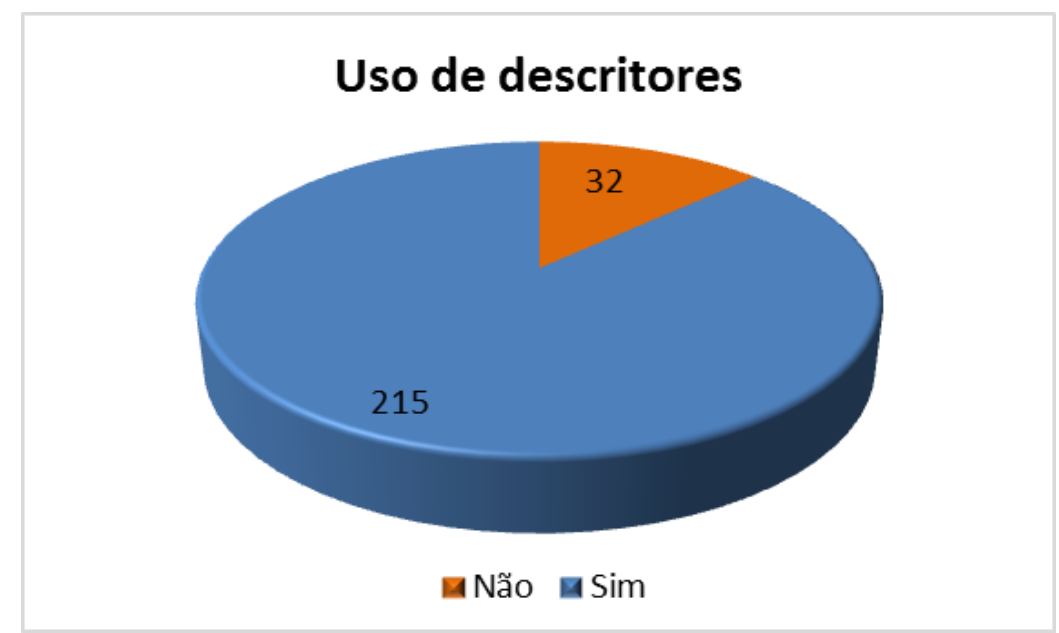


No Gráfico 11, os respondentes mostraram que a maioria (aproximadamente 79\%) participou de algum treinamento formal ou informal na Biblioteca. Este treinamento demonstra a mediação do bibliotecário na pesquisa de forma mais especializada e chegam a um resultado mais específico. Apenas um usuário não respondeu.

Gráfico 11. Treinamento na Biblioteca

\section{Treinamento na Biblioteca}

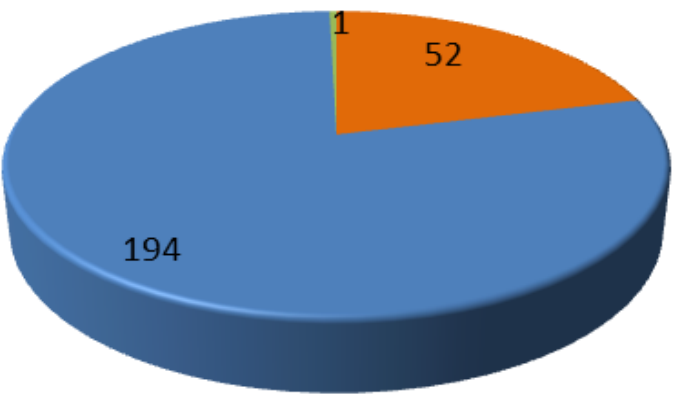

回 Não $\mathbf{a} \operatorname{Sim}$ Não respondeu

\subsection{Influencia da mediação no comportamento da população estudada}

Observamos diferença estatisticamente significativa entre os grupos no que diz respeito ao uso de descritores associado à mediação. Apesar de parecer influenciar positivamente a população de estudo no uso de descritores, mesmo os usuários não submetidos a qualquer tipo de mediação, já o faziam. Fica difícil se estabelecer relação direta neste caso.

Tabela 2 - Uso de descritores e treinamento crosstabulation

\begin{tabular}{|c|c|c|c|c|}
\hline & & \multicolumn{2}{|c|}{ Mediação } & \multirow{2}{*}{ Tota } \\
\hline & & não & sim & \\
\hline \multirow{2}{*}{ Descritores } & não & 0 & 32 & 32 \\
\hline & $\operatorname{sim}$ & 52 & 158 & 210 \\
\hline Total & & 52 & 190 & 242 \\
\hline
\end{tabular}

Fisher $\mathrm{p}<0,001$ 
Não observamos diferença significativa entre sexo (Tabela 3) ou profissão (Tabela 4) dos indivíduos participantes do estudo, em relação a receber ou não mediação.

Tabela 3: Distribuição do sexo dos participantes em relação à mediação

\begin{tabular}{cc|c|c|c}
\hline \multirow{2}{*}{} & & \multicolumn{2}{|c|}{ Mediação } & \multirow{2}{*}{} \\
\cline { 3 - 4 } & não & sim & \multirow{2}{*}{ Total } \\
\hline \multirow{2}{*}{ Sexo } & Masculino & 20 & 72 & 92 \\
& Feminino & 32 & 118 & 150 \\
Total & & 52 & 190 & 242 \\
\hline
\end{tabular}

Fisher $p=1$

Tabela 4: Profissão e mediação

\begin{tabular}{ll|c|c|c}
\hline \multirow{2}{*}{} & \multicolumn{2}{|c|}{ Mediação } & \multirow{2}{*}{ Total } \\
\cline { 3 - 4 } & não-médico & 27 & sim & \\
\hline \multirow{2}{*}{ Profissão } & Médico & 25 & 100 & 117 \\
& & 52 & 190 & 242 \\
\hline
\end{tabular}

Fisher $\mathrm{p}=0,639$

$\mathrm{Na}$ Tabela 5 podemos observar que não houve correlação entre a frequência de visitas à biblioteca e o fato de o usuário ter recebido alguma mediação.

Tabela 5: Frequência de visitas à biblioteca em relação à mediação

\begin{tabular}{ll|c|c|c}
\hline \multirow{2}{*}{} & & \multicolumn{2}{|c|}{ Treinamento } & \multirow{2}{*}{} \\
\cline { 3 - 4 } & Diariamente & não & sim & Total \\
\hline \multirow{2}{*}{ Frequência } & Semanalmente & 18 & 71 & 97 \\
& Quinzenalmente & 8 & 81 & 99 \\
Total & 52 & 190 & 242 \\
\hline
\end{tabular}

Pearson Chi square $p=0,239$ 
6 DISCUSSÃO 
$\mathrm{Na}$ pesquisa realizada na literatura nacional $\mathrm{e}$ internacional publicada entre 2001 e 2014, pudemos verificar que há vários trabalhos internacionais que destacam o papel do bibliotecário como facilitador entre a informação, as ferramentas e o pesquisador (Aitken et al., 2011; ALA, 2014; Galvão; Leite, 2008; Kurup; Hersey, 2007, Reis, 2013, Sherman, 2007).

Ao digitar uma palavra da linguagem corrente, recuperamos dezenas ou até centenas de telas, o que frustra o pesquisador que não dispõe de tempo suficiente para ler todas elas, como resultado da falta de uso de descritores ou palavras-chave. Se houvesse a presença de um bibliotecário para decidir a semântica na Web, o problema se resolveria (Miranda, 2010).

$\mathrm{Na}$ atualidade, a informação se tornou um elemento cada vez mais valorizado como viabilizador de decisões e de processos de conhecimento/inteligência nos diferentes campos. Há o assim chamado fenômeno da explosão informacional: grande quantidade de informações disponibilizadas dificultando sua identificação, acesso e utilização. De nada adianta a informação existir, se quem dela necessita desconhece que ela existe, ou se não puder ser encontrada (Marcondes, 2001).

Dos trabalhos recuperados no Brasil, destacamos Martinez-Silveira (2005); chamam a atenção para a função do bibliotecário que, como profissional da informação, especializado na área da saúde, tem um papel relevante a desempenhar, desde que apto no desenvolvimento de habilidades e conhecimentos específicos para atuação neste cenário de busca constante da informação.

Neste estudo, Martinez-Silveira (2005) afirma que a mediação do bibliotecário na área médica é muito comum em bibliotecas públicas, acadêmicas e/ou especializadas. Embora não haja no Brasil formação específica as habilidades se desenvolvem na prática e no atendimento diário atento às necessidades informacionais dos profissionais da área da saúde que procuram diariamente os serviços. 
Para Martinez-Silveira (2005), é fato, que diversas pesquisas ao redor do mundo atestam que esse tipo de usuário necessita dos recursos tecnológicos de informação e necessita das bibliotecas e dos profissionais da informação. E há todo um conjunto de instituições preocupadas em desenvolver recursos informacionais para os médicos na prática clínica. Mas não apenas isso. Os próprios médicos afirmam que esses recursos são fundamentais nesse meio-ambiente, que contribuem diretamente para decisões de saúde, em que a vida dos pacientes está em jogo.

Martinez-Silveira (2005), aponta para a figura do bibliotecário que como profissional da informação especializado na área da saúde, tem um papel importante a desempenhar, desde que detenha as habilidades $e$ conhecimentos específicos para sua atuação neste cenário de busca constante da informação. Afirma que a mediação do bibliotecário na área médica é muito comum em bibliotecas públicas, acadêmicas e/ou especializadas, embora não haja no Brasil formação específica para esse desempenho. A performance se constrói na prática e no atendimento diário e atento às necessidades informacionais do profissional da saúde ou do cidadão que procuram os serviços.

O papel do profissional da informação deve ser o de mediador da informação (Tarapanoff, 2002). O mediador, como facilitador da busca da informação, interage com o usuário no momento em que o entrevista a fim de entender seu problema e indicar um conjunto de fontes de informação que possam satisfazer suas necessidades informacionais (Reis, 2013). Além de identificar as fontes, ele ajuda o pesquisador a montar a estratégia de busca por meio de descritores e auxiliam ainda na busca do artigo completo, uma vez que as bases de dados, quase sempre apresentam apenas os resumos. 
O objetivo de uma biblioteca ou sistema de informação é, naturalmente, preencher algumas das necessidades de documentos e informações para os usuários atuantes ou potenciais. Tais necessidades podem, por exemplo, estar relacionadas a atividades educacionais, de investigação, culturais ou de desenvolvimento pessoal (Hjorland, 2014).

A gestão do conhecimento exige esta alta sintonia entre a coleta de informações e as ações que as disseminam e distribuem conforme a demanda do bibliotecário em questão. Por este motivo, o conhecimento deste público e o tipo de informação norteiam a atitude do bibliotecário para garantir sua assessoria e contribuição em um cenário de contínuas mudanças.

Entretanto, nosso trabalho apresenta muitas limitações no que diz respeito a provar a importância do mediador como fonte facilitadora. Falhamos em mostrar uma relação positiva entre o mediador e o usuário, provavelmente porque nossa ferramenta (questionário), não foi suficientemente sensível. Outra possibilidade é a de que os usuários, na maioria pós-graduandos e médicos acostumados a visitas frequentes à biblioteca, na verdade receberam mediação informal dos bibliotecários durante toda a sua vida acadêmica, sendo que o conhecimento e a prática para o uso das bases de dados foi-se expandindo naturalmente, e com um papel constante, porém pouco reconhecido do profissional da biblioteca. Sendo assim, ao ser questionado no presente, tal informação sobre ter recebido mediação se diluiu no tempo.

Outra grande limitação do presente estudo está relacionada a como definimos a mediação dispensada a estes usuários, foi considerada mediação qualquer intervenção ou auxílio prestado pelo bibliotecário durante sua ida à biblioteca, ou mesmo remotamente, por e-mail ou telefone. Ou seja, tal mediação é etérea e não homogenia e, portanto, difícil de se medir. 
Sendo assim, o presente estudo humildemente tenta discutir o tema da mediação nos dias de hoje e descrever uma amostra dos usuários mais frequentes da biblioteca da FMUSP nos últimos anos. Trata-se de um tema complexo, polêmico, da substituição do homem pela máquina, do valor imaterial e imensurável do contato humano nessa situação de expansão do conhecimento científico. Nesse estudo, portanto, tem sua validade ao lançar estas questões para reflexão da comunidade universitária e ao mesmo tempo para fomentar o surgimento de novas ideias e ressaltar a necessidade de atualização e aprimoramento constante do profissional da biblioteca em busca de novas ferramentas de trabalho e interação com o público, na busca do enriquecimento intelectual sempre aliado ao enriquecimento das relações humanas. 
7 CONCLUSÕES 
> O presente estudo permitiu caracterizar que a maioria dos usuários que compareceu à biblioteca era do sexo feminino e que estão na faixa etária entre trinta e nove e quarenta anos, sendo na maioria médicos jovens e estudantes de medicina, habituados a usar as bases de dados. A maioria recebeu algum tipo de mediação formal ou informal dos bibliotecários no acesso à informação. Sendo que este auxílio pode ter influenciado no uso de descritores em suas buscas.

Com esta pesquisa, foi possível avaliar algumas das necessidades informacionais dos respondentes. Tais informações aliadas a extensa revisão da literatura podem ser úteis para balizar futuras intervenções dos profissionais da biblioteca para otimizar seu papel na mediação. 


\section{CONSIDERAÇÕES FINAIS}


Cabe aos bibliotecários de referência ir além das buscas diárias, procurar adiantar-se a essas necessidades informacionais, estando atentos ao perfil dos usuários, bem como às novas ferramentas que aparecem diariamente na Internet. Deste modo, estarão à altura de participar da mudança de comportamento destes profissionais, porque contemplam três elementos principais deste cenário: a informação, as ferramentas para disseminá-la e o perfil do usuário.

Cresce, sem que se possa medir, num ritmo vertiginoso, o número de informações, porque a Internet tornou-se o veículo onde se disponibilizam informações às quais se tem acesso gratuito. Mas será que as fontes virtuais e a busca rápida são capazes de suprir as necessidades informacionais do pesquisador em qualidade e em tempo hábil?

No ano de 2013, a USP subiu uma posição e aparece entre as 10 melhores universidades em países emergentes. Está na 10a․ posição do Ranking Brics Times Higher Education.

Em um Informe da Reitora da Universidade de São Paulo de 29 de março de 2014, a USP encontra-se pela quarta vez no ranking da organização britânica Times Higher Education - principal avaliação internacional de instituições de ensino superior. Concorreu com instituições de mais de 300 anos e que estão situadas em países com muito mais bagagem histórica em matéria de cultura e geração de conhecimento. Isto se dá pelo número de alunos: 90 mil, sendo 2 mil doutores a cada ano na pesquisa e transmissão de conhecimento.

São treze os indicadores de desempenho que cobrem cinco aspectos considerados centrais:

Renda proveniente de pesquisa;

Ambiente de ensino;

Influência da pesquisa;

Volume de pesquisa; Posição no cenário internacional. 
Mais recentemente, foi divulgado pela empresa Britânica Quacquarelli Symonds, especializada em avaliação do ensino superior que a USP foi considerada a melhor universidade da América Latina, de acordo com o QS University Rankings. Isso acontece porque a universidade propicia formação de qualidade na graduação e pós-graduação em todas as áreas do conhecimento. A USP é também o mais importante centro de pesquisa nacional, responsável por mais de um quinto de todos os artigos especializados publicados no país, e principal instituto gerador de patentes (Zago, 2015).

Este crescimento no ranking se deve principalmente, ao nosso ver, no acesso à informação que através de sugestões, se adquire o material eletrônico ou impresso. Responsável pela aquisição do material atualizado, o bibliotecário procura também negociar preços, conseguir material para trials, organizar informação digital e preparar estatísticas para demonstrar aos administradores a necessidade de adquirir o acesso a informação atualizada e propiciar ao pesquisador acesso ao conhecimento do que é produzido no mundo. 
9 ANEXOS 


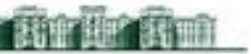 \\ MEDICINA \\ TTS \\ COMITÊ DE ÉTICA EM PESQUISA}

\section{APROVAÇÃO}

O Coordenador do Comitê de Ética em Pesquisa da Faculdade de Medicina da Universidade de São Paulo, em 19.10.2012, após atendimento a diligência encaminhada APROVOU ad-referendum o Protocolo de Pesquisa $\mathrm{n}^{\circ}$ 438/11, intitulado: "O Bibliotecário como mediador na informação biomédica.", apresentado pelo Programa de Fisiopatologia Experimental.

Cabe ao pesquisador elaborar e apresentar ao CEP-FMUSP, os relatórios parciais e final sobre a pesquisa .

Pesquisador (a) Responsável: Elnara Marcia Negri

Pesquisador (a) Executante: Marinalva de Souza Aragão

CEP-FMUSP, 19 de Outubro de 2012.

Pllaenum.

Prof. Dr.Roger Chammas

Coordenador

Comitê de Ética em Pesquisa 
ANEXO B. Termo de Consentimento Livre e Esclarecido e Questionário

FACULDADE DE MEDICINA DA UNIVERSIDADE DE SÃO PAULO TERMO DE CONSENTIMENTO LIVRE E ESCLARECIDO

DADOS DE IDENTIFICAÇÃO DO SUJEITO DA PESQUISA OU RESPONSÁVEL LEGAL

1. NOME:

DOCUMENTO DE IDENTIDADE № : SEXO : .M $\square \quad F$ DATA NASCIMENTO:

ENDEREÇO № APTO:

BAIRRO: CIDADE CEP: TELEFONE: DDD

\section{DADOS SOBRE A PESQUISA}

1. TÍTULO DO PROTOCOLO DE PESQUISA: 0 bibliotecário como mediador na informação biomédica.

PESQUISADOR: Marinalva de Souza Aragão

CARGO/FUNÇÃO: Bibliotecária........... INSCRIÇÃO CONSELHO REGIONAL № CRB 8/4368

UNIDADE DO HCFMUSP: Divisão de Biblioteca e Documentação da FMUSP.

3. AVALIAÇÃO DO RISCO DA PESQUISA: $\quad$ RISCO MÍNIMO $\quad X \quad$ RISCO MÉDIO

RISCO BAIXO $\quad \square \quad$ RISCO MAIOR

4.DURAÇÃO DA PESQUISA : 24 meses 


\section{FACULDADE DE MEDICINA DA UNIVERSIDADE DE SÃO PAULO}

1. Essas informações estão sendo fornecidas para sua participação voluntária neste estudo, que tem por objetivo avaliar a necessidade de auxilio por parte de um profissional de biblioteca aos médicos e alunos de pós-graduação da Faculdade de Medicina na realização de pesquisas bibliográficas e da busca de informações na área da saúde. Por isso vamos entrevistar um total de 150 usuários da Biblioteca Central da FMUSP via e-mail e/ou presencial.

2. Serão aplicados questionários aos alunos de pós-graduação e aos profissionais da área biomédica, via e-mail;

3. Somente no final do estudo poderemos concluir a presença de algum benefício direto para o participante. Trata-se de estudo experimental testando a hipótese de que o bibliotecário possa auxiliar o aluno e o profissional a buscar a informação com maior rapidez e relevância;

4. Garantia de acesso: em qualquer etapa do estudo, você terá acesso aos profissionais responsáveis pela pesquisa para esclarecimento de eventuais dúvidas. O principal investigador é a Dra. Elnara Márcia Negri, que pode ser encontrada na Av. Dr. Arnaldo, 455, 3o andar ou por e-mail emnegri@yahoo.com.br;

5. Se você tiver alguma consideração ou dúvida sobre a ética da pesquisa, entre em contato com o Comitê de Ética em Pesquisa (CEP) - Av. Dr. Arnaldo, 455 - Instituto Oscar Freire - 1ำ andar- tel: 3061-8004, FAX: 3061-8004- E-mail: cep.fmusp@hc.fm.usp.br;

6. É garantida a liberdade da retirada de consentimento a qualquer momento e deixar de participar do estudo, sem qualquer repercussão para o voluntário;

7. Direito de confidencialidade - As informações obtidas serão analisadas em conjunto, não sendo divulgada a identificação de nenhum dos voluntários;

8. Direito de ser mantido atualizado sobre os resultados parciais da pesquisa, quando em estudos abertos, ou de resultados que sejam do conhecimento dos pesquisadores; 
9. Despesas e compensações: não há despesas pessoais para o participante em qualquer fase do estudo. Também não há compensação financeira relacionada à sua participação.

10. Compromisso do pesquisador de utilizar os dados coletados somente para esta pesquisa.

Acredito ter sido suficientemente informado a respeito das informações que li ou que foram lidas para mim, descrevendo o estudo: "O bibliotecário como mediador na informação biomédica"

Eu discuti com a Dra. Elnara Marcia Negri sobre a minha decisão em participar nesse estudo. Ficaram claros para mim quais são os propósitos do estudo, os procedimentos a serem realizados, garantias de confidencialidade e de esclarecimentos permanentes. Ficou claro também que minha participação é isenta de despesas e que tenho garantia do acesso às informações. Concordo voluntariamente em participar deste estudo e poderei retirar o meu consentimento a qualquer momento, antes ou durante o mesmo, sem penalidades ou prejuízo ou perda de qualquer benefício que eu possa ter adquirido, ou no meu atendimento neste Serviço.

Assinatura do entrevistado

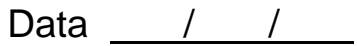

\section{(Somente para o responsável do projeto)}

Declaro que obtive de forma apropriada e voluntária o Consentimento Livre e Esclarecido deste pesquisador na participação neste estudo.

11




\section{Perfil dos usuários da Biblioteca em 2012: necessidade de mediação?}

1. Com que frequência acessa informações de sua área?
C Diariamente
Semanalmente
(C) Quinzenalmente
2. Para atualizar-se, você utiliza
Base de dados
Informações por e-mail
Consulta colegas
(C) Google Scholar
Lilacs
(5) Medline
(C) Scopus

3. Você usa alguma base de dados específica?

4. São suficientes os resumos?

(C) Sim

C. Não

5. Para conseguir o artigo completo, você utiliza:

Biblioteca

Internet/Periódicos on-line

6. Há uso de descritores?

(C) Sim

7. Já participou de treinamentos na biblioteca?

(C) Sim

Não

\section{Qual sua idade?}

\section{Qual sua atuação?}

10.Sexo

(C) Feminino

(C) Masculino 
9 REFERÊNCIAS 
American Library Association. Value of academic libraries: a comprehensive research review and report [online]. Chicago, IL: Association of College and Research Libraries (ACRL); 2010 [cited 2014 Apr 17]. Available from: http://www.acrl.ala.org/value.

Aitken EM, Powelson SE, Reaume RD, Ghali WA. Involving clinical librarians at the point of care: results of a controlled intervention. Acad Med. 2011;86:150812.

Arellano MAM. Serviços de referência virtual. Ci Inf. 2001;30:7-15.

Aun R. A vocação médica e a academia. Diagn Tratamento. 2014;19:139-40.

BIREME. Biblioteca Virtual em Saúde. DeCS - Descritores em ciências da saúde [citado 12 mar. 2014]. Disponível em: http://decs.bvs.br.

Blansit BD, Connor E. Making sense of the electronic resource marketplace: trendes in health-related electronic resources. Bull Med Libr Assoc. 1999;87:243-50.

Brandau R, Monteiro R, Braile DM. Importância do uso correto dos descritores nos artigos científicos. Rev Bras Cir Cardiovasc. 2005;20:7-9.

Brettle A, Hulme C, Ormandy P. Effectiveness of information skills training and mediated searching: qualitative results from the EMPIRIC project. Health Inform Libr J. 2007;24:24-33.

Burford S, Park S. The impact of mobile tablet devices on human information behaviour. J Doc. 2014;70(4):622-39.

Cardoso ONP, Machado RTM. Gestão do conhecimento usando data mining: estudo de caso na Universidade Federal de Lavras. RAP (Rio de Janeiro). 2008;42:495-528. 
Cardoso SC. Panorama da produção científica da Faculdade de Medicina da Universidade de São Paulo no período 2001-2006 [dissertação]. São Paulo: Universidade de São Paulo, Faculdade de Medicina; 2009.

Carvalho ICL. A socialização do conhecimento no espaço das bibliotecas universitárias. Niterói: Intertexto; 2004. p.19-21.

Cendón BV. Ferramentas de busca na Web. Ci Inf. 2001;30:39-49.

Cervo AL, Bervian PA. Metodologia científica. 6a ed. São Paulo: Prentice Hall; 2007.

Cleveland AD, Holmes KL, Philbrick JL. Genomics and translactional medicine for information professionals: an innovative course to educate the next generation of librarians. J Med Lib Assoc. 2012;100:303-5.

Curran VR, Fleet LJ, Kirby F. A comparative evaluation of the effect of internetbased CME delivery format on satisfaction, knowledge and conference. Med Educ. 2010 [cited 2013 March 23]. Available from: http://www.biomedcentral.com/1472-6920/10/10.

Dee C, Stanley EE. Information-seeking behavior of nursing students and clinical nurses: implications for health sciences librarians. J Med Libr Assoc. 2005;93:213-22.

Dias MMK, Belluzzo RCB, Pinho FA, Pires D. Capacitação do Bibliotecário como mediador do aprendizado no uso de fontes de informação. Rev Dig Bibliotecon Ci Inf. 2004;2:1-16. 
Felício JCSM. Serviço de Referência Educativo (SER) em bibliotecas universitárias: análise das práticas voltadas ao desenvolvimento da competência em informação de seus usuários [dissertação]. Florianópolis: Programa de pós-graduação em Ciência da Informação da Universidade Federal de Santa Catarina; 2014.

Ferreira DT. Profissional da informação: perfil de habilidades demandadas pelo mercado de trabalho. Ci Inf. 2003;32:42-9.

Ferreira LC. Gestão e uso da informação na produção científica. In: Duarte EM, Paiva SB, Silva AKA, organizadores. Múltiplas abordagens da gestão da informação e do conhecimento. João Pessoa: Editora UFPB; 2014. p.52-69.

Ferreira LE, Almeida Júnior OF. A mediação da informação no âmbito da arquivística. Perspect Ci Inf. 2013;18:158-67.

Fleury MTL, Fleury A. Construindo o conceito de competência. Rev Admin Contemp - RAC. 2001:183-96.

Ford J, Korjonen $\mathrm{H}$. Information needs of public health practitioners: a review of the literature. Health Inform Libr J. 2012;29:260-73.

Galvão MCB, Leite RAF. Do bibliotecário médico ao informacionista: traços semânticos de seus perfis e competências. Trans/nformação. 2008;20:181-91.

Garbin HBR, Pereira Neto AF, Guilam MCR. A internet, o paciente expert e a prática clínica: uma análise bibliográfica. Interface. 2008;12:579-88.

Garcia CLS, Almeida Júnior OF, Valentim MLP. O papel da mediação da informação nas universidades. Rev EDICIC. 2011;1:351-9 [Acesso 4 jan. 2015]. Disponível em http://www.edicic.org/revista. 
Gasque KCGD. Pesquisas na pós-Graduação: o uso do pensamento reflexivo no letramento informacional. Ci Inf. 2011;40:22-37.

Grefsheim SF, Whitmore SC, Rapp BA, Rankin JA, Robinson RR, Canto CC. The informationist: building evidence for an emerging health profession. $J$ Med Libr Assoc. 2010;98:147-56.

Gomes MYFSF. Desafios atuais da Ciência da Informação no Brasil. Perspect Ci Inf. 2009;14:190-205.

Guevara S. Generation Y what can we do for you. Inform Out.2007;11:81-2.

Hjorland B. Information needs [cited 2014 March 05]. Available from: http://www.iva.dk/bh/Core\%20Concepts\%20in\%20LIS/articles\%20az/information_needs.htm.

Koufogiannakis D, Buckingham J, Alibhait A, Rayner D, Scott JW. Impact of librarians in first-year medical and dental student problem-based learning (PBL) groups: a controlled study. Health Inf Libr J. 2005;22:189-95.

Kuhlthau CC. Accommodating the user's information search process: challenges for information retrieval system designers [cited 2014 Aug. 06]. Bull Am Soc Inf Sci. 1999;25. Available from: http://www.asis.org/Bulletin/Feb99/kuhlthau.html.

Kurup V, Hersey D. The perioperative librarian: luxury or necessity? Curr Opin Anaesthesiol. 2007;20:585-9.

Lauritsen J, Moller AM. Clinical relevance in anesthesia journals. Curr Opin Anaesthesiol. 2006;19:166-70. 
Libâneo JC. Adeus professor, adeus professora? Novas exigências educacionais e profissão docente. 7a ed. São Paulo: Cortez; 2003.

Marcondes CH. Representação e economia da informação. Ci Inf. 2001;30:619.

Marteleto RM. O lugar da cultura no campo de estudos da informação: cenários prospectivos. In: Lara MLG, Fujino A, Noronha DP, organizadores. Informação e contemporaneidade: perspectivas. Recife: Néctar; 2007. p.17-8.

Martínez-Silveira MS. A informação científica na prática médica: estudo do comportamento informacional do médico-residente [dissertação]. Salvador: Instituto de Ciência da Informação, Universidade Federal da Bahia; 2005.

Miranda GF, Gualtieri F, Coccia P. How the new Web generations are changing library and information services. Med Ref Serv Q. 2010;29:132-45.

Moraes MB. As transformações dos processos de mediação da informação nos currículos de formação do bibliotecário brasileiro no contexto da sociedade da informação [dissertação]. São Paulo: Universidade de São Paulo, Escola de Comunicações e Artes; 2012.

Neves BC. Mediação da informação para agentes sociodigitais: o salto. Ci Inf. 2011;40:413-24.

Nobre AAC. Identificação de competências relevantes aos profissionais da Polícia do Senado Federal [Monografia-Lato Sensu]. Brasília: Faculdade de Economia, Administração, Contabilidade e Ciência da Informação e Documentação - FACE; 2005. 
Patridge H, Menzies V, Lee J, Munro C. The contemporary librarian: skills, knowledge and a tributes required in a world of emerging technologies. Library Inform Sci Res. 2010;32:265-71.

Perrotti E, Pieruccini I. Infoeducação: saberes e fazeres da contemporaneidade. In: Lara MLG, Fujino A, Noronha DP, organizadores. Informação e contemporaneidade. Recife: Nectar; 2007. p.52.

Reis FM. A atuação do bibliotecário em ambientes corporativos: um estudo sobre GED [Trabalho de Conclusão de Curso]. São Paulo: Escola de Comunicações e Artes, Universidade de São Paulo; 2013.

Rethlefsen $\mathrm{ML}$, Murad $\mathrm{MH}$, Livingston $\mathrm{EH}$. Engaging medical librarians to improve the quality of review articles. JAMA. 2014;312:999-1000.

Rodrigues BC, Crippa G. A recuperação da informação e o conceito de informação: o que é relevante em mediação cultural? Perspec Ci Inform. 2011;16:45-64.

Sherman W. Reasons why libraries and librarians are still extremely important. Inf Outlook. 2007;11:67-78.

Silva MC. Mediação cultural: reflexões a partir da teoria histórico-cultural. In: Congresso Nacional de Psicologia Escolar e Educacional - ABRAPEE; 6-8 jul. 2009.

Singh SP. What are we managing - knowledge or information? [cited 2013 Feb 15]. Available from: http://www.emeraldinsight.com/0305-5728.htm.

Sousa MM. A biblioteca universitária como ambiente de aprendizagem no ensino superior [dissertação]. São Paulo: Universidade de São Paulo, Escola de Comunicação e Artes; 2009. 
Souto LF. Mediação em serviços de disseminação seletiva de informações no ambiente de bibliotecas digitais federadas [tese]. São Paulo: Universidade de São Paulo, Escola de Comunicações e Artes; 2008.

Souza L. Prevalência de sintomas depressivos, ansiosos e estresse em acadêmicos de medicina [tese]. São Paulo: Faculdade de Medicina, Universidade de São Paulo; 2010.

Tarapanoff K, Suaiden E, Oliveira CL. Funções sociais e oportunidades para profissionais da informação. DataGramaZero: Rev Ci Inf. 2002 [citado 31 maio 2011]. Disponível em: http://www.dgz.org.br/out02/Art_04.htm.

Valentim MLP, Cavalcante LFB. Mediação da informação e comportamento informacional. Disponível em: http://www.ofaj.com.br/colunas_conteudo_print.php?cod+465.

Xavier RCM, Costa RO. Relações mútuas entre informação e conhecimento: o mesmo conceito? Ci Inf. 2010;39(2):75-83.

Zarifian P. O modelo da competência: trajetória histórica, desafios atuais e proposta. São Paulo: Senac; 2003.

Zago MA. A USP é tudo isso. Folha de S. Paulo. 2014, mar. 29.

Zago MA. A número 1 da América Latina. J USP. 2015 jun.;31(1068). 


\section{BIBLIOGRAFIA CONSULTADA}


Bussab WO, Siqueira JO, Daibes ALL, Kira SH. Como construir um questionário: delineamento de um roteiro para a sua elaboração. São Paulo: IME; 1989. Série: RAE-SEA-8924.

Castro CA. História da biblioteconomia brasileira: perspectiva histórica. Brasília: Thesaurus; 2000. p.115-287.

Cervo AL, Bervian PA. Metodologia científica. 5a ed. São Paulo: Prentice Hall; s.d.

Consani MA. Mediação tecnológica na educação: conceitos e aplicações. São Paulo: Universidade de São Paulo, Escola de Comunicações e Artes; 2008. Disponível em: http://www.teses.usp.br/teses/disponíveis/27/27154/ tde-27042009-115431/pt-br.php.

Marconi MA, Lakatos EM. Fundamentos de metodologia científica. 6a ed. São Paulo: Atlas; 2007.

Nahas FX, Ferreira LM. A arte de redigir um trabalho científico. Acta Cir Bras. 2005;20(supl. 2):17-8.

Secaf V. Artigo científico: do desafio à conquista. Jundiaí: Reis Editorial; 2000.

Vieira S. Como elaborar questionários. São Paulo: Atlas; 2009.

Volpato G. Dicas para redação científica. 3a ed. rev. ampl. São Paulo: Cultura Acadêmica; 2010.

Williams B, Brown T, McKenna, Palermo C, Morgan, Nestel D, et al. Student empathy levels across 12 medical and health professions: an interventional study. J Compassion Health Care. 2015:2:4-9. 